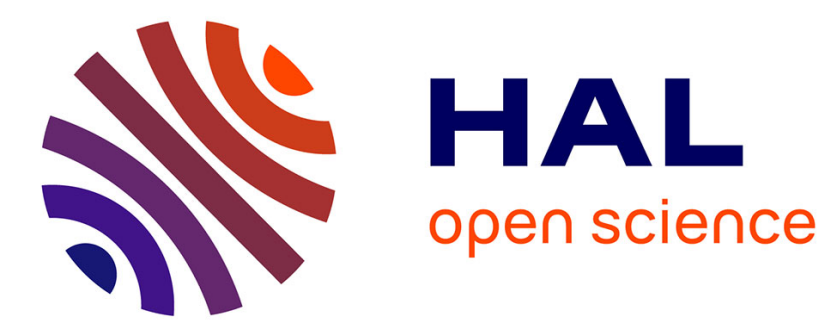

\title{
Origin of Regular Networks of Joints: Experimental Constraints, Theoretical Background, and Numerical Modeling
}

A. Chemenda

\section{- To cite this version:}

A. Chemenda. Origin of Regular Networks of Joints: Experimental Constraints, Theoretical Background, and Numerical Modeling. Journal of Geophysical Research: Solid Earth, 2019, 10.1029/2019JB017454 . hal-02372767

\section{HAL Id: hal-02372767 https://hal.science/hal-02372767}

Submitted on 21 Sep 2021

HAL is a multi-disciplinary open access archive for the deposit and dissemination of scientific research documents, whether they are published or not. The documents may come from teaching and research institutions in France or abroad, or from public or private research centers.
L'archive ouverte pluridisciplinaire HAL, est destinée au dépôt et à la diffusion de documents scientifiques de niveau recherche, publiés ou non, émanant des établissements d'enseignement et de recherche français ou étrangers, des laboratoires publics ou privés.

$$
\text { Copyright }
$$




\author{
RESEARCH ARTICLE \\ 10.1029/2019JB017454 \\ Key Points: \\ - Parallel joint sets were generated in \\ three-layer FD elastoplastic models \\ that include tensile and shear failure \\ with different brittleness \\ - Joints are initiated as dilation \\ deformation bands and propagate to \\ different distances across the layer \\ following the band propagation \\ - Band thickness in the models is \\ proportional to the material ductility \\ (pressure) as is also suggested by the \\ experimental data
}

Correspondence to: A. I. Chemenda,

chem@geoazur.unice.fr

Citation:

Chemenda, A. I. (2019). Origin of regular networks of joints:

Experimental constraints, theoretical background, and numerical modeling. Journal of Geophysical Research: Solid Earth, 124, 9164-9181. https://doi.org/ 10.1029/2019JB017454

Received 29 JAN 2019 Accepted 24 JUN 2019 Accepted article online 2 JUL 2019 Published online 13 AUG 2019

\section{Origin of Regular Networks of Joints: Experimental Constraints, Theoretical Background, and Numerical Modeling}

\author{
A. I. Chemenda ${ }^{1}$ \\ ${ }^{1}$ University of Côte d'Azur, CNRS, OCA, IRD, Geoazur, Valbonne, France
}

\begin{abstract}
Experimental data show that inelastic straining occurs even at very low pressure before and during brittle fracturing. This process is therefore investigated within the framework of elastoplasticity using 2-D, three-layer finite difference modeling. The constitutive model includes both tensile and shear failure mechanisms coupled at the level of the strain softening law. The modeling results show that sets of parallel joints initiate as pure dilation bands, the narrow $\sigma_{3}$-normal bands of localized dilatant damage (inelastic deformation). The band thickness, length, and the initial strain softening degree within it are proportional to the ductility of the material, which increases with the effective stress level $\left(\sigma_{1}\right)$ or pressure. The strength reduction within the bands is accelerated at a certain stage, and the strength locally reaches zero resulting in fracture initiation. The initial fracture then propagates in Mode I following the propagating band. The fracture (joint) appears thus as a band of damaged material with the increased porosity, which is maximum along the axial zone of the band where the material is completely broken. The damage is due to both tensile and shear mechanisms. The role of shear failure increases with the ductility (pressure) increase, which also leads to the band thickness increase. These processes can result in small (band thickness)-scale oblique shear fractures within the band, causing the increase in the roughness of fracture walls organized in plumose patterns typical of both natural and experimentally generated joints.
\end{abstract}

\section{Introduction}

Planner fractures (joints) with no shear displacement along them often form spectacular parallel sets or more complex (e.g., orthogonal) networks, which affect weakly deformed tabular sedimentary series. Good geological images can be found, for instance, in Pollard and Aydin (1988), Rives et al. (1992), Engelder et al. (2009), Jorand et al. (2012), and Fossen (2016). One of them is shown in Figure 1. It reveals the fracture hierarchy in 3-D, which otherwise is hardly visible and which was also obtained in the numerical models in this paper and the laboratory experiments (see below). The regularity of the spatial organization of joints suggests uniformity of the material properties and straining during jointing, which also means a uniform stress field. On the other hand, the commonly accepted jointing mechanism, Mode I fracturing, treated within the framework of Linear Elastic Fracture Mechanics (LEFM), requires the presence of stress concentrators, that is, the initial flaws from which the fractures (joints) propagate in Mode I (e.g., Bai \& Pollard, 2000; Olson et al., 2009; Pollard \& Aydin, 1988; Savalli \& Engelder, 2005; Segall \& Pollard, 1983). In the numerical studies explaining joint propagation within the framework of LEFM (i.e., assuming that the complete material rupture directly follows the elastic loading in a very small zone at the fracture tip), unrealistically high initial flaw sizes (lengths) $a$ have to be adopted. For example, Olson et al. (2009) assumed $a=10 \mathrm{~cm}$; Bai and Pollard (2000) obtained that for Mode I cracks to form with a spacing less than the bed thickness $H$ of several tens of centimeters, $a$ should be of a centimeter scale. To obtain smaller spacing, $a$ should be larger. The minimum possible spacing was predicted to be $\sim 0.3 H$. These conclusions were obtained for the favorable case when the initial cracks are normal to $\sigma_{3}$. If they are inclined to $\sigma_{1}$, the fracturing will be more complicated (involving the formation of curvilinear wing cracks; e.g., Ashby \& Sammis, 1990; Petit \& Barquins, 1988). The actual size of the initial flaws should to be comparable to the grain size, although macroflaws (that can be stress concentrators) can exist as well (McConaughy \& Engelder, 2001).

In many cases, joints are not opened at all and appear as discontinuities with no discernable relative displacements (Blès \& Feuga, 1986; Griggs \& Handin, 1960; Ramsay \& Huber, 1987) that can correspond to porosity or dilation (dilatancy) bands (Chemenda et al., 2011b). This type of band, although not related to joints, 


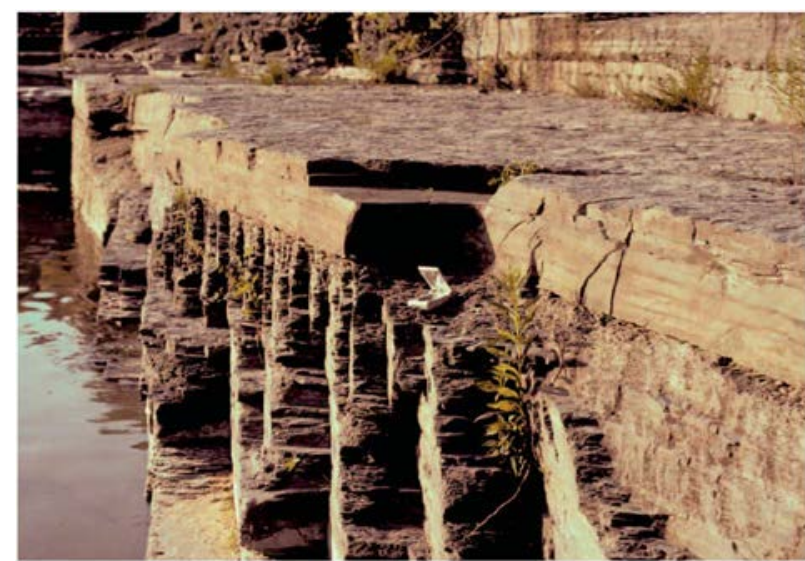

Figure 1. Joints in a thick shale bed (Taughannock Falls State Park, New York) emanating from the bed top and propagating downward to different distances. Compass is for the scale. From Younes and Engelder (1999) and Engelder et al. (2009). A photo of the same outcrop is given by Pollard and Aydin (1988). also was documented in Du Bernard et al. (2002) and Fossen et al. (2007). These discontinuities can be very closely spaced (e. g., Rawnsley et al., 1998) up to almost constituting a rock fabric (Figure 3c in Jorand et al., 2012). It is difficult to imagine that at the origin of each of the closely spaced joints, there is a specific flaw of a centimeter scale.

Walls of joints are frequently decorated by plumose marks analyzed in detail in many studies (e.g., Bahat, 1991; Pollard \& Aydin, 1988; Savalli \& Engelder, 2005; Woodworth, 1896). Pollard and Aydin (1988) and numerous authors since suggest that the plumose morphology of joints results from mostly Mode I joint propagation with contribution of Modes II and/or III. Unfortunately, no direct evidence of this exists. Since we do not know (cannot observe or measure) the actual conditions and mechanisms of natural jointing, such evidence could be provided by laboratory experiments reproducing joint-like fractures with plumose marks in rock or rock-like (i.e., granular, porous, frictional, dilatant, and cohesive) materials under geologically meaningful physical conditions. We are aware only of a few relevant experimental studies presented below.

\subsection{Experimental Constraints on Jointing Mechanisms}

As joints are believed to be formed under extension, the most relevant are data from extension tests of porous rocks. Bobich (2005) reported results from conventional (axisymmetric) triaxial extension tests of hard Berea sandstone under different, relatively low confining pressure $P_{c}$ (which is equal in this test type to the major $\sigma_{1}$ and the intermediate $\sigma_{2}$ stresses), corresponding to brittle fracture (we use a rock mechanics convention, for which $\sigma_{1} \geq \sigma_{2} \geq \sigma_{3}$, the compressive stress is positive and the tensile stress is negative). Both joints and shear fractures were obtained in these tests (for joints, the angle $\psi$ between the fracture and the $\sigma_{1}$-direction is approximatively zero, whereas shear fractures are inclined to $\sigma_{1}$ ).

Chemenda et al. (2011a) conducted similar tests on Granular Rock Analogue Material (GRAM1) made of very small bonded $\mathrm{TiO}_{2}$ grains (Nguyen et al., 2011). The mechanical properties of this material have been extensively studied (Mas \& Chemenda, 2014, 2015; Nguyen et al., 2011). It was shown to behave very similarly to hard rocks, showing the same pressure dependence of properties (Figure 2) and variation of the dilatancy factor from positive to negative values with $P_{c}$ increase. GRAM1, however, is much weaker (about 2 orders of magnitude) than real rocks as can be seen in Figure 2.

Fractures of the same types as in Berea sandstone were generated in the GRAM1 extension tests. The minimum stress $\sigma_{3}$ at fracturing is shown in Figure 3 as a function of $\sigma_{1}$ for both GRAM1 and Berea sandstone with the indication of the domains of jointing and shear fracturing (defined by the $\psi$ value). In spite of the very different nature and strength of these materials, the curves have similar trends (as is also the case in Figure 2 under different loading conditions).

Figure 4 shows surfaces of the $\sigma_{3}$-normal $(\psi=0)$ fractures generated in GRAM1 extension tests. One can clearly see that the roughness of these surfaces increases with $P_{c}$, which suggests that the thickness of the failure zone (or band) increases as well with $P_{c}$ (it is logical to suppose that the amplitude of the roughnesses is related/proportional to the thickness of the failure zone). These roughnesses are organized in plumose patterns (Figures 4d-4f) that reflect a propagating character of the rupture. The plumose morphology of fracture surfaces was not reported in the Berea sandstone tests. A possible reason could be a large grain size of the sandstone, $\sim 200 \mu \mathrm{m}$. The grain size of GRAM1 is sufficiently small $(\sim 0.3 \mu \mathrm{m})$ for the plumose features to be well displayed on small specimen sections of $\sim 3 \mathrm{~cm}$ of diameter (the Berea sandstone specimens have the same diameter). What are the causes of the roughening of the fracture surface (the thickening of the fracture zone or band)? The stress-strain curves in Figure 5 from the described tests suggest a possible answer. This figure shows that even at a very small pressure corresponding to what is called brittle fracturing, the curves deviate from linearity before the fracture formation for both GRAM1 and Berea sandstone. This deviation increases with $P_{c}=\sigma_{1}$ (which is particularly well seen for GRAM1) and attests to the inelastic deformation (material damage) preceding the rupture and certainly accompanying it. The latter, however, 


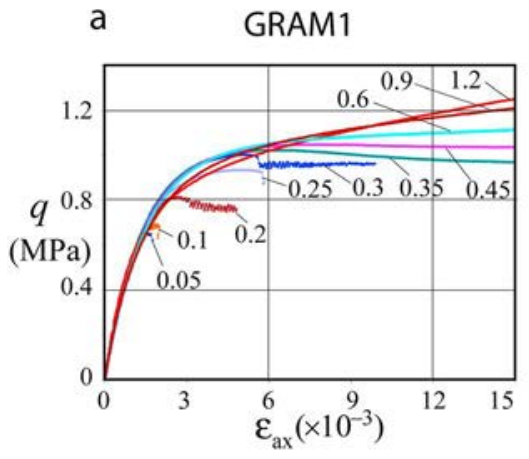

C

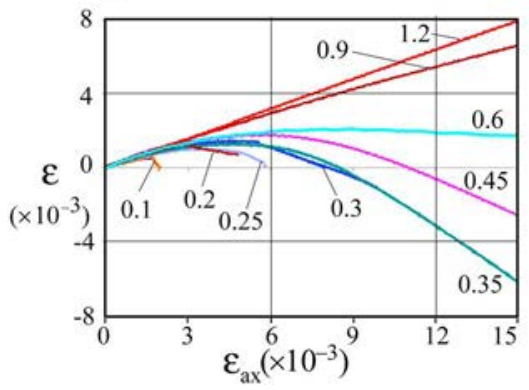

b Solnhofen limestone

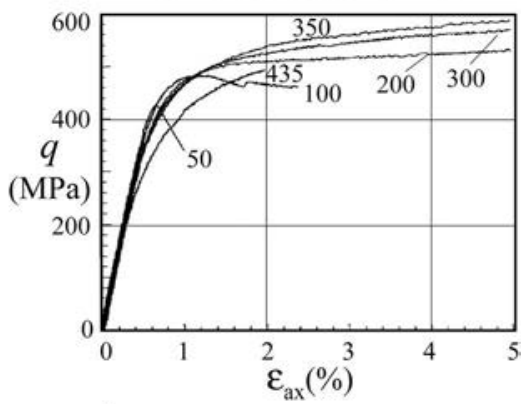

d

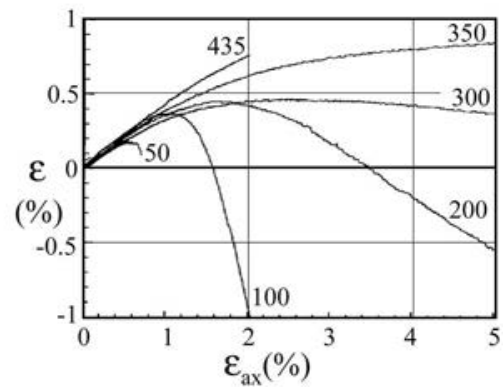

Figure 2. Comparison of the stress-strain curves obtained from conventional axisymmetric compression tests for GRAM1 (a and c; from Nguyen et al., 2011) and Solnhofen limestone (b and d; from Baud et al., 2000) at different $P_{c}$ indicated near the corresponding curves in MPa. $q$ is the differential stress $\left(q=\sigma_{1}-\sigma_{3}, \sigma_{3}=\sigma_{2}=P_{c}\right)$, $\varepsilon$ and $\varepsilon_{a x}$ are the nominal volume and axial strains, $\varepsilon_{a x}=\varepsilon_{1}$.

cannot be derived directly from the nominal (average) stresses and strains measured in the tests and presented in Figure 5. On the other hand, a more ductile character of fracture (lesser stress drop) at higher $P_{c}$ is seen in Figure 5a.

It is the increase of inelastic strain (or ductility) with $P_{c}$ that is likely responsible for the thickening of the rupture zone (band) and roughening the surface of the final fracture. In any case, the rupture does not follow directly the elastic straining (as is assumed in LEFM) but is preceded and accompanied by an inelastic deformation (for both GRAM1, Figure 5a, and a hard rock, Figure 5b) that must be taken into account. In fact, the increase of ductility (reduction of brittleness) with $P_{c}$ is well known from the numerous experimental studies
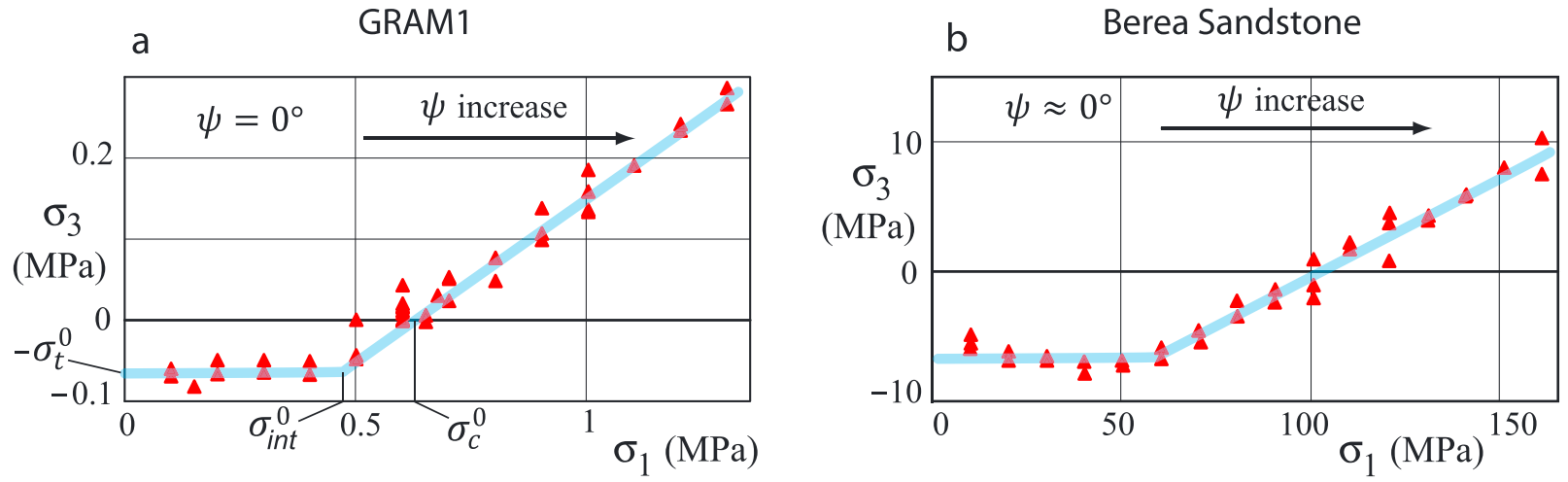

Figure 3. Minimum principal stress $\sigma_{3}$ versus confining pressure $P_{c}=\sigma_{1}$ at fracturing/rupture in conventional (axisymmetric, $\sigma_{1}=\sigma_{2}$ ) extension tests of GRAM1 (a) and Berea sandstone (b). Data for sandstone are from Bobich (2005) and for GRAM1 from Nguyen et al. (2011) and Chemenda et al. (2011a). $\psi$ is the angle between the fracture plane and $\sigma_{1}$ direction; $\sigma_{t}^{0}$ and $\sigma_{c}^{0}$ are the initial tensile and uniaxial compression strengths; $\sigma_{\text {int }}^{0}$ is the abscissa of the intersection point of the horizontal and inclined blue lines approximating the experimental data. 

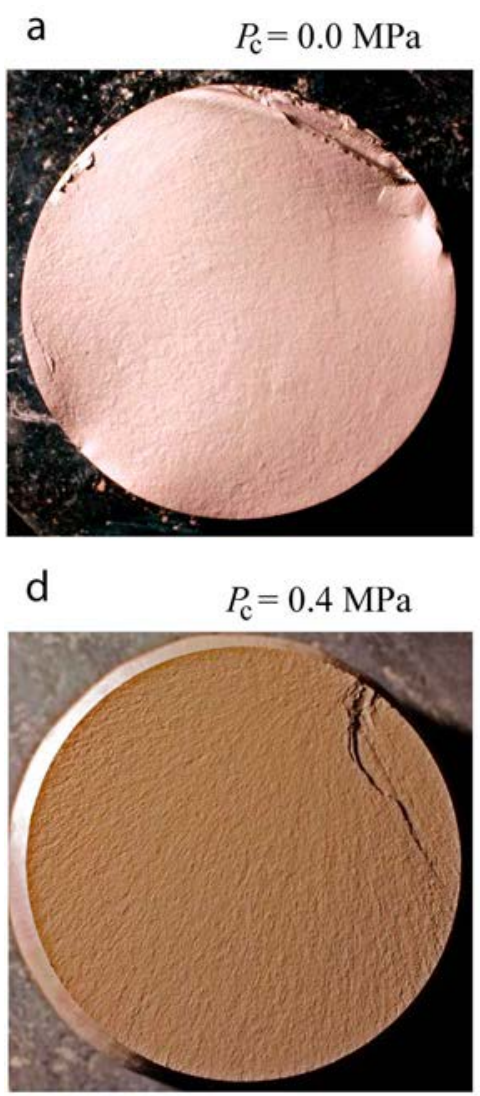

b
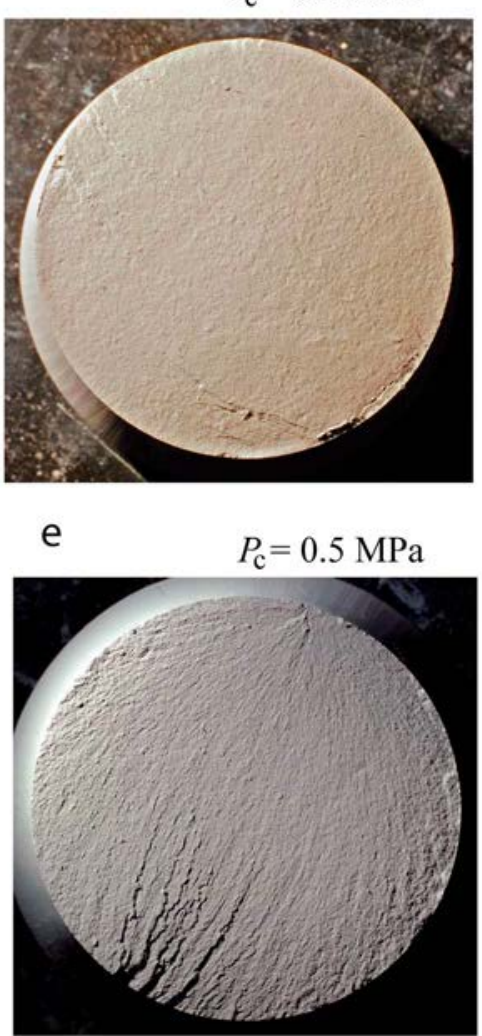
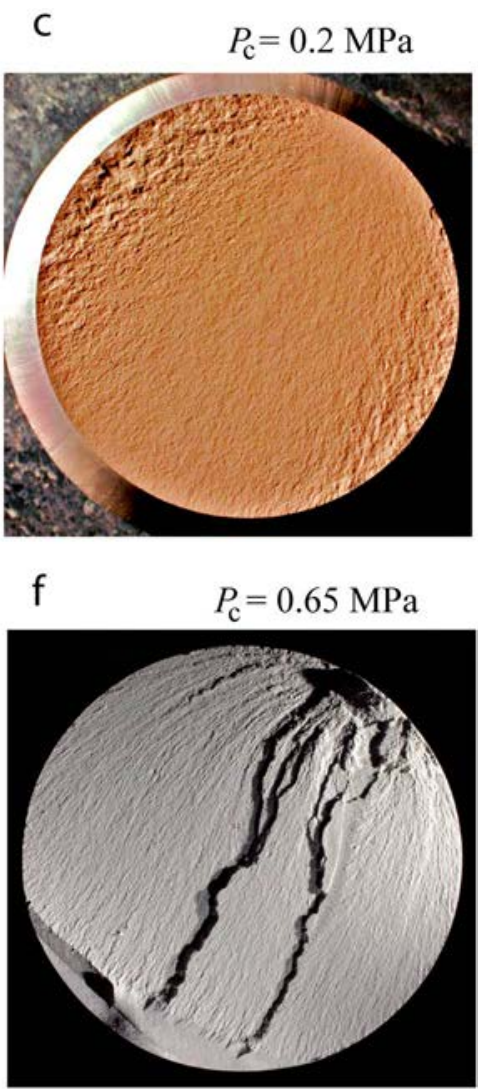

$15 \mathrm{~mm}$

Figure 4. Surfaces of $\sigma_{3}$-normal fractures generated in GRAM1 specimens in axisymmetric extension tests under different confining pressures $P_{c}$ (from Chemenda et al., 2011a).

and results in the transition from $\sigma_{1}$-parallel $(\psi \approx 0)$ to $\sigma_{1}$-oblique (shear, $\left.\psi>0\right)$ fracturing (e.g., Bésuelle et al., 2000; Fortin et al., 2006; Nguyen et al., 2011; Wong et al., 1997; Wong \& Baud, 2012). The plots in Figure 5 show that this is true even within a narrow range of small $P_{c}$ corresponding to the same fracture orientation (or type), $\psi \approx 0$. Thus, the plumose morphology obtained in the experimental fracture surfaces at elevated pressure (Figures $4 \mathrm{~d}-4 \mathrm{f}$ ) is likely to be due to the increase in ductility of the fracture process. Therefore, the elastoplastic framework seems to be more suitable than LEFM to address this process. The macrofracturing is of course affected by the defects/flaws intrinsic to geomaterials at micro (grain and grain
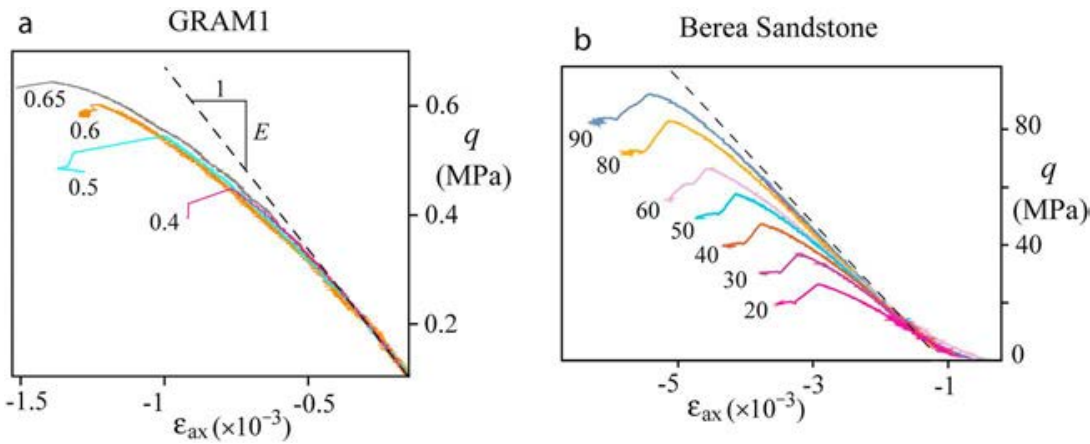

Figure 5. Nominal stress-strain curves from axisymmetric extension tests on GRAM1 (Chemenda et al., 2011a) and Berea sandstone (Bobich, 2005) at different confining pressures $P_{c}=\sigma_{1}$ indicated on the plots in MPa. $E$ is the Young modulus for GRAM1, $E=6.7 \times 10^{8} \mathrm{~Pa}$ (Mas \& Chemenda, 2014). 


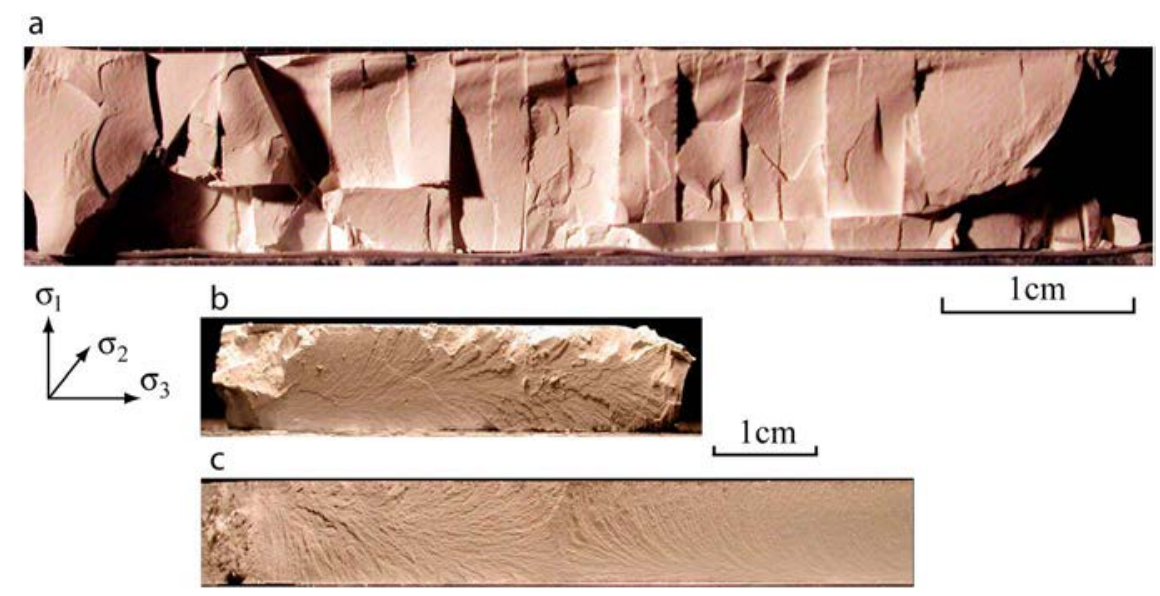

Figure 6. Set of parallel joints (a) normal to $\sigma_{3}$ generated in a GRAM2 layer sandwiched between two rubber layers in plane-strain experiments using true 3-D loading device (GRAM2 is similar to but somewhat weaker than GRAM1). Three-layer model initially prestressed in three directions hydrostatically was unloaded in the $\sigma_{3}$ direction under planestrain conditions at constant vertical stress $\sigma_{1}=0.22 \mathrm{MPa}$. The principal stress directions shown refer only to (a). The fracture surfaces in (b and c), formed in this experiment, are normal to $\sigma_{3}$. These results are from (Jorand et al., 2012).

agglomerate) scale, but not in the way that one (or a few) defects give rise to a macrofracture. The actual fracturing (e.g., jointing) process seems rather occur by the interaction and coalescence (localization) of numerous defects (heterogeneities) distributed within the deforming volume. These cannot be analyzed individually, and the challenge is to formulate a constitutive model that on the one hand is sufficiently simple and physically transparent, and on the other hand, correctly captures the material damage resulting in macrofracturing.

It is important to distinguish the formation of regular fracture networks in tabular sedimentary piles over vast areas from that of local individual fractures that can be related to the local stress perturbations (concentration) of different origin. We focus on the fracture network formation, which can hardly be understood as a simple sequential addition of individual brittle cracks (Rives et al., 1992). A mechanism should exist that would enable the development of a regular damage pattern within a sedimentary volume from the beginning. Such a process (initiation of regular networks of deformation localization bands evolving to fractures) can occur in elastoplastic materials (Chemenda, 2007, 2009), resulting from a material (or constitutive) instability (Rudnicki \& Rice, 1975; Rice, 1976). For this mechanism to work, the inelastic straining before fracturing is a necessary ingredient, which exists according to the curves in Figure 5. This is an additional motivation to apply an elastoplastic approach.

Finally, in the presented axisymmetric extension tests, only one fracture can be generated, which does not correspond to the sets of parallel joints observed in nature. The reason is in the boundary conditions applied in these tests to the cylindrical surface of specimens; pressure is applied by the confining fluid with no stiffness. In nature, the most common situation is when jointing affects certain layers within a multilayer sedimentary pile, and so a more pertinent experimental setup should include at least three layers, with the central one undergoing fracturing. This setup was used in the plane strain extension tests by Jorand et al. (2012), where a layer of GRAM2 material (similar to but weaker than GRAM1) was sandwiched between two rubber layers. Sets of parallel plumose-bearing joints were generated in these experiments (Figure 6a). A similar setup is used in the numerical models in this paper.

\section{Constitutive Framework for Modeling of Jointing}

\subsection{Yield Function}

The shape of the yield surface for the tensile fracturing follows from the experimental data in Figure 3 . They can be approximated by two linear segments, the horizontal and the inclined ones as is done in Figure 3. The horizontal segment is defined by one parameter, the tensile strength $\sigma_{t}$ (or the initial tensile strength $\sigma_{t}^{0}$ shown in Figure 3a), and the inclined segment, by two parameters, the slope $\alpha_{c}$ and the uniaxial (or 


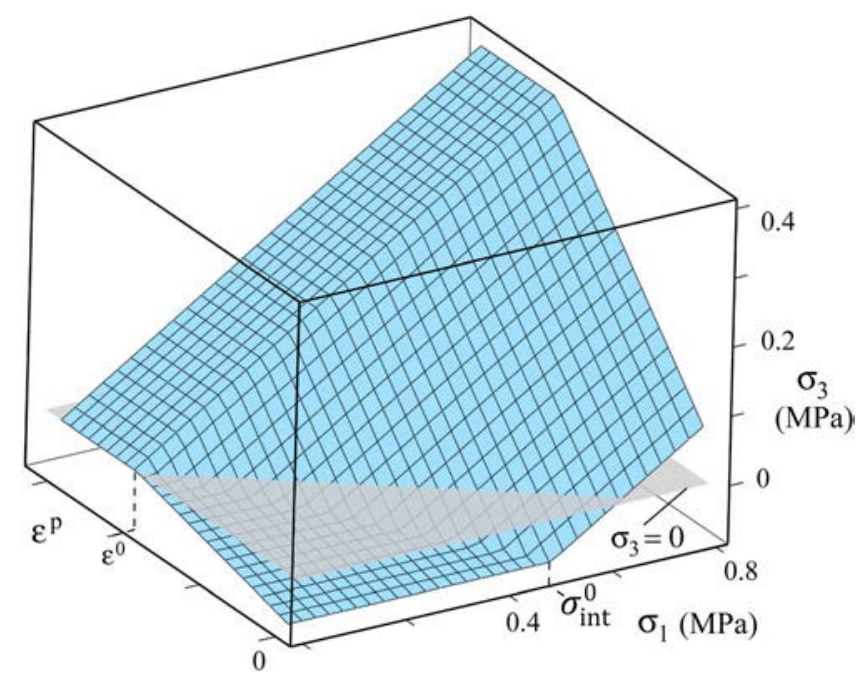

Figure 7. Composite yield surface $\sigma_{3}\left(\sigma_{1}, \varepsilon^{p}\right)$. The gray semitransparent plane shows a zero-level $\sigma_{3}$. unconfined) compression strength $\sigma_{c}$ (assuming the Mohr-Coulomb model, $\alpha_{c}$ and $\sigma_{c}$ can be expressed in terms of internal friction angle and cohesion).

Since we consider low-pressure loading conditions corresponding to the dilatant-brittle deformation regime, the inelastic straining should lead to material softening (strength reduction). Assume that $\alpha_{c}$ remains constant, and both strengths $\sigma_{t}$ and $\sigma_{c}$ reduce linearly with the accumulated inelastic extension or volume $\varepsilon^{p}$ strain, reaching zero at $\varepsilon^{p}=\varepsilon^{0}$ (superscript $p$ stands for plastic or inelastic). The composite yield function is plotted in Figure 7 and reads

$$
F= \begin{cases}F_{t}=\sigma_{t}+\sigma_{3} & \text { if } \sigma_{1} \leq \sigma_{\mathrm{int}} \\ F_{s}=\alpha_{c} \sigma_{3}+\sigma_{c}-\sigma_{1} & \text { if } \sigma_{1}>\sigma_{\mathrm{int}}\end{cases}
$$

where $F_{t}$ and $F_{s}$ are the yield functions for the tensile and shear failure mechanisms, respectively (Figure 3 ), and $\sigma_{t}, \sigma_{c}$, and $\sigma_{\text {int }}$ are functions of $\varepsilon^{p}$ (Figure 7)

$$
\begin{array}{ll}
\sigma_{t}\left(\varepsilon^{p}\right)=\sigma_{t}^{0} \kappa\left(\varepsilon^{p}\right), \sigma_{c}\left(\varepsilon^{p}\right)=\sigma_{c}^{0} \kappa\left(\varepsilon^{p}\right), \sigma_{\text {int }}\left(\varepsilon^{p}\right)=\sigma_{\text {int }}^{0} \kappa\left(\varepsilon^{p}\right) & \text { if } \varepsilon^{p} \leq \varepsilon^{0} \\
\sigma_{t}\left(\varepsilon^{p}\right)=\sigma_{c}\left(\varepsilon^{p}\right)=\sigma_{\text {int }}\left(\varepsilon^{p}\right)=0 & \text { if } \varepsilon^{p}>\varepsilon^{0}
\end{array}
$$

where $\kappa\left(\varepsilon^{p}\right)=1-\varepsilon^{p} / \varepsilon^{0}, \sigma_{c}^{0}$, and $\sigma_{\text {int }}^{0}$ are the initial values of $\sigma_{t}, \sigma_{c}$, and $\sigma_{\text {int }}$ (see Figure $3 a$ ).

\subsection{Plastic Potential Function}

A dominant damage mechanism of compact rocks in axisymmetric compression tests at low-stress levels (both in terms of $P_{c}$ and $\sigma_{1}$ during the loading compared to the values of these stresses at failure) is dominantly $\sigma_{1}$-parallel microfracturing (e.g., Dunn et al., 1973; Hallbauer et al., 1973; Katz \& Reches, 2004; Tapponnier \& Brace, 1976; for a review see Paterson \& Wong, 2005). More relevant, although very scarce axisymmetric extension (Rodriguez, 2005) and true 3-D (Chang \& Haimson, 2000; Ma \& Haimson, 2016) experimental studies show that $\sigma_{1}$-parallel and $\sigma_{3}$-normal microcracking occurs to higher stress levels. Within the framework of a classical elastoplasticity theory, this process corresponds to the negative (extension) inelastic strain $\varepsilon_{3}^{p}$, whereas $\varepsilon_{1}^{p}$ and $\varepsilon_{2}^{p}$ can be neglected up to a certain stress level that we assume to be $\sigma_{1}=\sigma_{\text {int }}$.

The flow rule in the principal stress space reads

$$
d \varepsilon_{i}^{p}=d \lambda \frac{\partial \Phi}{\partial \sigma_{i}}
$$

where $\Phi$ is the plastic potential function, $d \lambda$ is the nonzero scalar function ( $d \lambda$ is different for the different failure mechanisms introduced), and $i=1,2,3$. Since for the tensile failure only $d \varepsilon_{3}^{p} \neq 0$, the corresponding plastic potential $\Phi_{t}$ is equal to $F_{t}$; that is, the plasticity is associated and the inelastic strain increment is normal to the yield surface. Assume also the normality rule for the shear failure mechanism in the brittledilatant deformation regime considered. Then the composite plastic potential $\Phi$ is simply equal to $F$ from (1) with an accuracy up to constant coefficients.

The above constitutive formulation is similar to the classical one based on Rankine (cutoff) and MohrCoulomb criteria. The novelty is that both tensile and shear failure mechanisms are coupled in the presented model by a synchronous evolution of both strengths $\left(\sigma_{t}\right.$ and $\left.\sigma_{c}\right)$ during the inelastic straining: if one decreases, the other does the same and, when one reaches zero, the other does as well (Figure 7). One can further rectify (and hence complicate) the model to incorporate more experimental observations. For example, $\varepsilon^{0}$ can be introduced as a function of the stress level (of $\sigma_{1}$ or the mean stress) so that $\varepsilon^{0}$ (or ductility) increases with $\sigma_{1}$ as stated in the Introduction and follows from Figure 5. However, we prefer to keep the model as simple as possible and to test the influence of $\varepsilon^{0}$ on the failure (fracturing) processes by simply varying this parameter in the numerical models. For the same sake of simplicity, we use the Mohr-Coulomb-type 
yield function for shear failure/damage, which is justified by the fact that in this paper we focus on the fracturing that is mostly defined by the tensile failure mechanism. For fracturing at higher pressure where the shear failure mechanism plays a major role, more adequate (but more complex as well) three-invariant, $\sigma_{2}$-dependent constitutive models (e.g., Chemenda \& Mas, 2016; Rudnicki, 2017) should be used.

Since $\varepsilon_{2}^{p}=0$ and $\varepsilon_{1}^{p}$ is either zero (for the tensile failure mechanism) or small (for the dilatant-shear deformation), $\varepsilon^{p} \approx \varepsilon_{3}^{p} \approx \gamma^{p}$, where $\gamma^{p}$ is the maximum inelastic shear strain $\left(\gamma^{p}=\varepsilon_{3}^{p}-\varepsilon_{1}^{p}\right)$. Therefore, either of strains $\varepsilon^{p}, \varepsilon_{3}^{p}$, or $\gamma^{p}$ can be used to track the history of inelastic deformation and to define the softening. The numerical simulations lead to practically the same results in all these cases. As is seen from the expressions (2), we use $\varepsilon^{p}$ in this paper.

\subsection{Integration of Mesh Element Size of Numerical Models Into the Constitutive Formulation}

The failure/fracturing process we study results from a mechanical instability leading to deformation localization. The numerical finite difference (FD) or finite element modeling of this process is known to be mesh dependent (e.g., Needleman, 1988; Pijaudier-Cabot \& Bažant, 1987). The thickness of the deformation localization bands (of the failure zone) is directly proportional to the mesh element size $\Delta z$ and typically is equal to (1-4) $\Delta z$ depending on the orientation of the mesh anisotropy axes with respect to the orientation of the forming deformation bands (e.g., Chemenda, 2007). The solution therefore does not converge with mesh refinement. To reduce (remove) the mesh dependency, different regularization (notably nonlocal/gradient) techniques are applied (e.g. Chen \& Schreyer, 1987; Needleman, 1988; Nguyen \& Korsunsky, 2008; Pijaudier-Cabot \& Bažant, 1987; Poh \& Swaddiwudhipong, 2009; Vardoulakis, 1989) in order to smooth the deformation field and thereby stabilize the band thickness when refining the grid. This is done through the introduction of an intrinsic length, which should ideally be the grain size. Using these techniques, the numerical band thickness $d$ can indeed be stabilized and include as many grid zones as necessary. The stress-strain response of the model during band formation and evolution does not change in this case with the grid refinement. However, for the same constitutive model, this response will change with $d$ change and will approach the response of the modeled (physical) object as $d$ approaches the physical (real) band thickness $d_{R}$, which is typically very small and equal to several grain sizes. This means that the discretization should be finer than $d_{R}$, which is impossible when addressing most of the real-life geological problems. Therefore, exact modeling is impossible in this case with or without regularization. Rather sophisticated, computationally expensive regularization procedures that do not always have a clear physical meaning therefore lose their initial attractiveness as a means of obtaining more rigorous solutions. On the other hand, since the mechanical response of the numerical model is $\Delta z$-dependent, this parameter has to be an integral part of the constitutive formulation. It should be noted that discrete element method models do not escape from this requirement either. They were shown to be particle size (and also particle shape) dependent. Ideally, this size should be comparable to the grain size of the modeled rock (which is impossible in most cases) or at least be included in the constitutive formulation (e.g., Potyondy \& Cundall, 2004).

In the FD models reported in this paper, $\Delta z$ is included into the constitutive description in the following simple manner. Since the thickness of a strain localization band (failure zone) is proportional to $\Delta z$, the strain rate, and hence the material softening rate within the failure zone, is inversely proportional to $\Delta z$. In other words, to produce the same softening in the model within the band with different mesh element sizes $\Delta z_{0}$ and $\Delta z_{1}\left(\Delta z_{1}<\Delta z_{0}\right)$, less work by the external (boundary) forces is needed when $\Delta z$ is smaller, that is, when $\Delta z=\Delta z_{1}$. The softening rate and the dynamics of strain localization (of failure) are defined by the hardening modulus $h$. For the tensile failure

$$
h=\frac{1}{G} \frac{\partial \sigma_{t}}{\partial \varepsilon^{p}}
$$

where $G$ is the shear modulus. To obtain the same softening in the models with different $\Delta z$ at the same loading stage, $h$ should be scaled as $h_{0} \Delta z_{1}=h_{1} \Delta z_{0}$. Considering relations (2), obtain from (4)

$$
\varepsilon_{1}^{0}=\frac{\Delta z_{0}}{\Delta z_{1}} \varepsilon_{0}^{0}
$$

where subscripts 0 and 1 correspond to different mesh element sizes (or mesh resolution). The simple way 


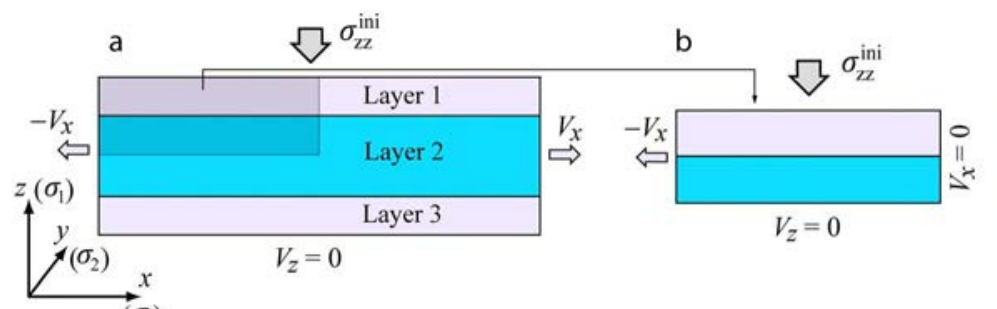

C

$\left(\sigma_{3}\right)$

Figure 8. Setup of three-layer 2-D numerical models. (a) The entire model. (b) A quarter of the entire model. (c) The attached two layers of the grid used to reduce the grid anisotropy that can influence the strain localization. The velocity and stress boundary conditions applied are shown in (a) and (b); $V_{x}$ and $V_{z}$ are the velocities in the corresponding directions. $\sigma_{z z}^{\text {ini }}$ is the initial stress in the $z$ direction to which the models are prestressed; this stress is also applied to the upper boundary of the models during the deformation. Layers 1 and 3 are purely elastic, and their thickness is $0.5 \mathrm{~cm}$. Layer 2 is elastic-plastic; its thickness is $1 \mathrm{~cm}$. The length of the entire model is $4 \mathrm{~cm}$.

thus to reduce the mesh dependency of the deformation pattern and its evolution in numerical models is to express $\varepsilon^{0}$ in the constitutive relations as

$$
\varepsilon^{0}=\tilde{\varepsilon}^{0}(C / \Delta z)
$$

where $C$ is a constant coefficient, and $\widetilde{\varepsilon}^{0}$ is equal to $\varepsilon^{0}$ when $\Delta \mathrm{z}=C$.

The formulated constitutive model has been implemented into the FD dynamic time-matching explicit code FLAC3D (Itasca, 2013) used for the numerical modeling in this work. The elastic properties are modeled by Hooke's equations. Numerous simulations were carried out in quasi-static, large-strain mode with different model parameters. Below we report representative results.

\section{Modeling Setup}

A plane-strain, three-layer model is subjected to the velocity and stress boundary conditions, as shown in Figure 8a. Layers 1 and 3 are purely elastic, and layer 2 has elastoplastic properties described above. The adjacent layers are totally coupled. The model parameters are close to those in GRAM experiments in Chemenda et al. (2011a) and Jorand et al. (2012). The elastic properties of all the layers in the presented models are the same, $E=6.7 \times 10^{8} \mathrm{~Pa}$ and $\nu=0.25$ and are those for GRAM1 ( $E$ is Young's modulus and $\nu$ is Poisson's ratio); $\sigma_{t}^{0}, \sigma_{c}^{0}, \sigma_{\text {int }}^{0}$, and $\alpha_{c}$ are defined from the plot in Figure 3a to be $\sigma_{t}^{0}=7 \times 10^{4} \mathrm{~Pa}, \sigma_{c}^{0}=6.5 \times$ $10^{5} \mathrm{~Pa}$, and $\sigma_{\text {int }}^{0}=5.1 \times 10^{5} \mathrm{~Pa}, \alpha_{c}=2$ (see also Figure 7). The models are prestressed to the initial stresses $\sigma_{x x}^{\text {ini }}$ and $\sigma_{z z}^{\text {ini }}=\sigma_{y y}^{\text {ini }} ; \sigma_{x x}^{\text {ini }}$ is set close to (but less negative than) $-\sigma_{t}^{0}$ to approach the failure point in order to save the calculation time, and $\sigma_{z z}^{\text {ini }}=\sigma_{y y}^{\text {ini }}$ are varied, but in the presented models they are $\sigma_{z z}^{\text {ini }}=\sigma_{y y}^{\text {ini }}=3.5 x$ $10^{5} \mathrm{~Pa}$ (the average of the values applied in the GRAM1 experiments in Figure 4), except in the model in Figure 13, where $\sigma_{z z}^{\text {ini }}=\sigma_{y y}^{\text {ini }}=6 \times 10^{5} \mathrm{~Pa}$. The vertical stress $\sigma_{z z}=\sigma_{z z}^{\text {ini }}$ is applied to the upper model boundary as shown in Figure 8a. The parameter $\varepsilon^{0}$ is difficult to define from the experimental data, and in addition, it is mesh-dependent (equation (6)). Therefore, it is varied in a wide range by varying $\widetilde{\varepsilon}^{0}$ from $5 \times 10^{-2}$ to $5 \times 10^{-4}$, the coefficient $C$ being set to $2.5 \times 10^{-4} \mathrm{~m}$. The model size is given in the caption of Figure 8 . The model resolution (numerical grid size) was varied as well. It is given in the figure captions by the number of grid elements $N_{x}$ in the $x$ direction.

Figure 8a shows the complete modeled structure, but to reduce the calculation time, most of the simulations have been carried out with the model reduced to a quarter shown in Figure 8b. The boundary conditions applied to these models also are shown in this figure.

Although the models are 2-D, they have two attached grid layers in the $y$ direction with different geometry of grid elements of layer 2 (Figure 8c). This considerably reduces the grid anisotropy that may affect strain localization.

It should be noted that although the models were run with the specified model parameters, the results will be the same for other parameters with the dimension of stress $(\mathrm{Pa})$ if they are properly scaled. The most 


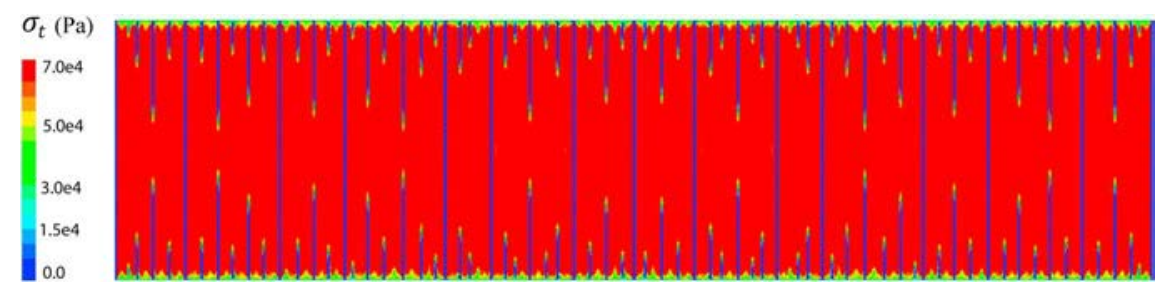

Figure 9. The result of fracturing (expressed in terms of the tensile strength $\sigma_{t}\left(\varepsilon^{p}\right)$ ) of the entire model (corresponding to Figure 8a) after horizontal extension run at $\widetilde{\varepsilon}^{0}=10^{-3}, N_{x}=640$, and $\sigma_{z z}^{\text {ini }}=\sigma_{y y}^{\text {ini }}=3.5 \times 10^{5} \mathrm{~Pa}$. Here and below, only the middle layer (layer 2, Figure 8a) is shown.

important thing is to keep the same $\sigma_{c}^{0} / \sigma_{t}^{0}$ ratio, which is equal to $\sim 9$ for the chosen (GRAM1) parameters. This value is typical for brittle rocks.

\section{Modeling Results}

Below we present results from nine numerical simulations, run with the parameters given above and in the captions of the corresponding figures. Figure 9 shows the complete fractured model corresponding to the setup in Figure 8a, and Figure 10 presents the evolution of a quarter of this model (corresponding to the setup in Figure 8 b) for the relatively brittle material behavior (small $\widetilde{\varepsilon}^{0}$ value, equal to $10^{-3}$ ). A synchronous evolution of $\sigma_{t}, \sigma_{3}$, and of the mechanical state during the horizontal extension, showing damage/failure mechanisms (tensile or shear) and their history, is presented in Figure 10. At the initial stages of fracture formation, $\sigma_{t}$ within them is close to $\sigma_{t}^{0}=7 \times 10^{4} \mathrm{~Pa}$ and then decreases to zero when the fracture is completely formed. The two fractures at the model ends in Figure 9 (the leftmost fracture

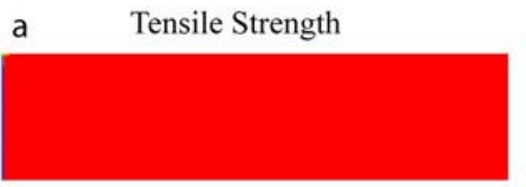

b

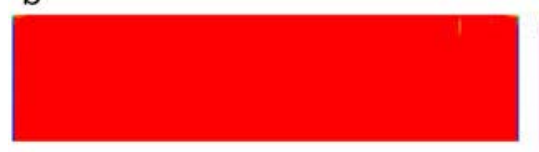

C

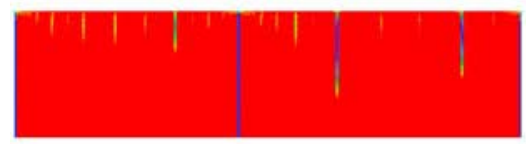

d

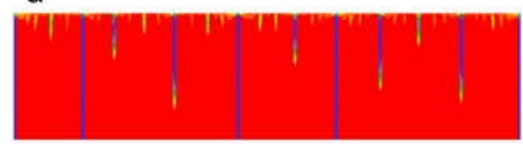

e

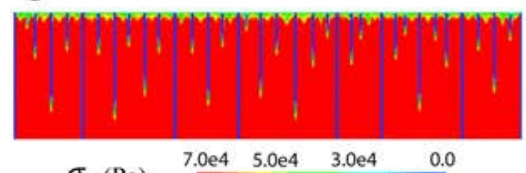

$\sigma_{t}(\mathrm{~Pa}) \quad \begin{array}{llll}7.0 \mathrm{e} 4 & 5.0 \mathrm{e} 4 & 3.0 \mathrm{e} 4 & 0.0\end{array}$
Mechanical State
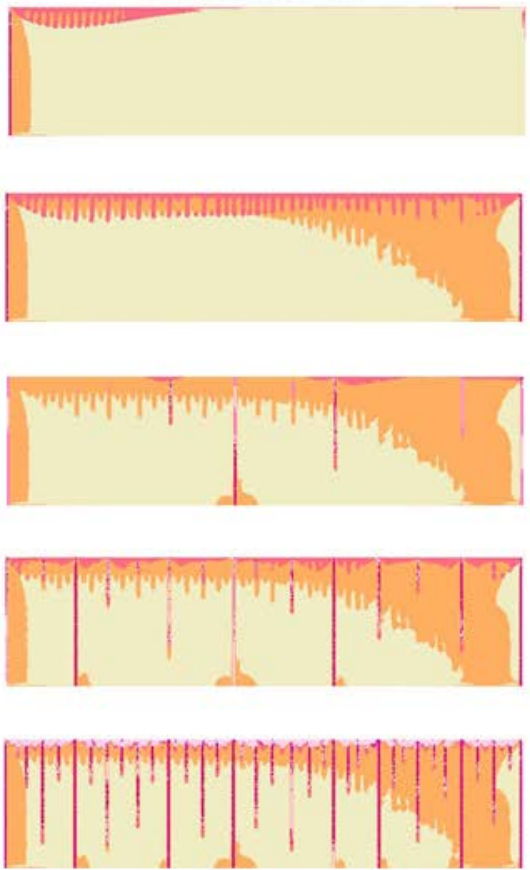

purely elastic

tens-n, shear-p, tens-p shear-n, shear-p, tens-p
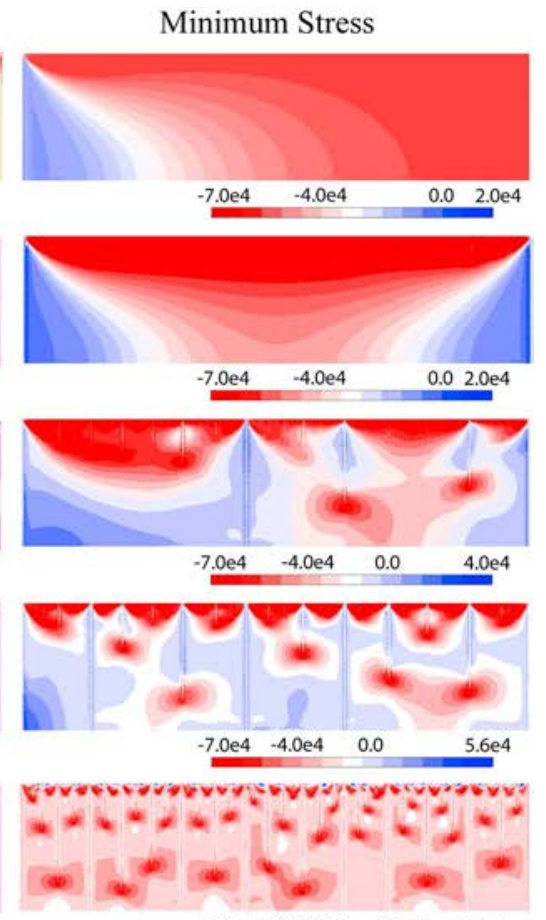

$\sigma_{3}(\mathrm{~Pa}) \quad-6.9 \mathrm{e} 4 \quad-4.0 \mathrm{e} 4 \quad 0.0 \quad 8.0 \mathrm{e} 4 \quad 1.4 \mathrm{e} 5$

Figure 10. Five stages (lines a to e) of the evolution of $\sigma_{t}$, the mechanical state, and $\sigma_{3}$ during the horizontal extension in a quarter of the entire model corresponding to the setup in Figure 8b. Mechanical state (elastic and elastic-plastic) plots show damage/failure or inelastic deformation mechanism (tensile or shear) and its history. Different colors in these plots correspond to different damage mechanisms and their succession. For example, "tens-n (n means now), shear-p, tens- $p$ ( $p$ means past)" indicate that the corresponding zones undergo a tensile damage at the stage shown, but they already underwent shear and tensile damage during previous deformation stages (in the past). Zones shown as pure elastic did not undergo inelastic straining at all. $N_{x}=320$. 
a
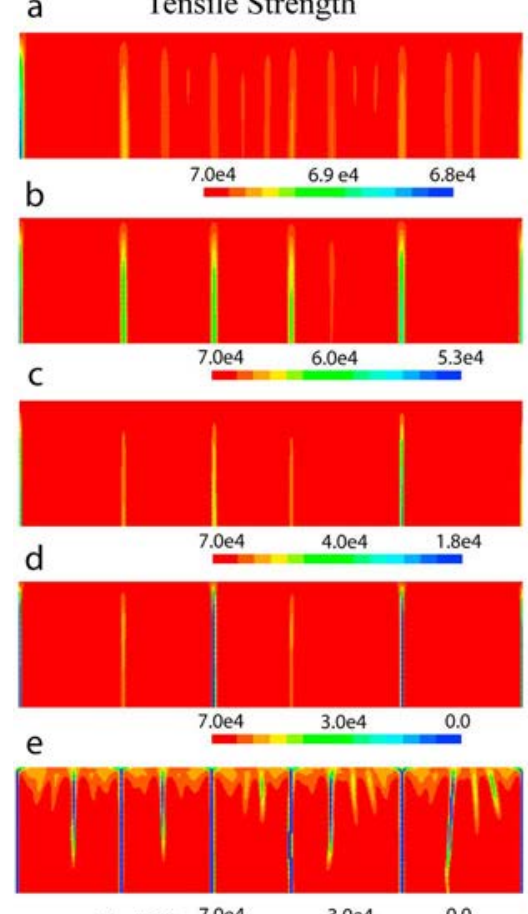

$\sigma_{t}(\mathrm{~Pa}) \quad 7.0 \mathrm{e} 4$
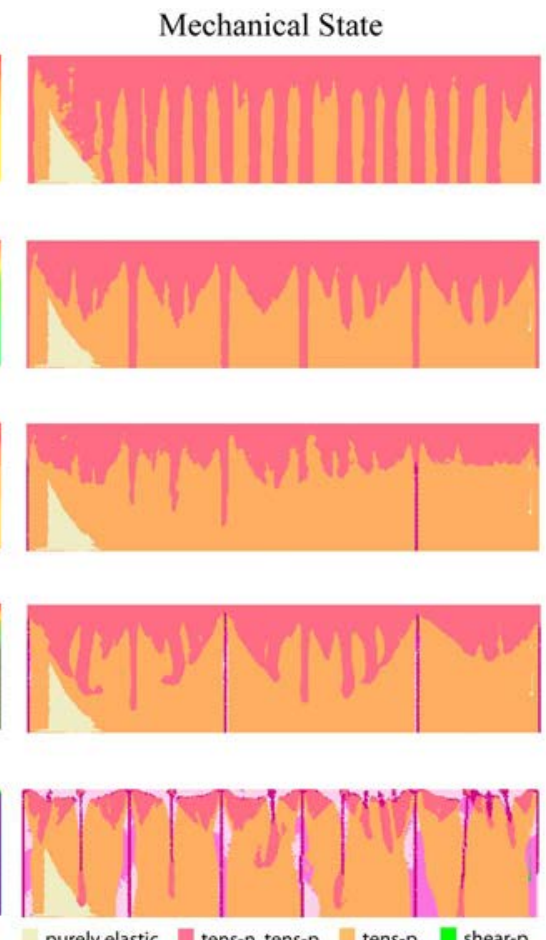

purely elastic च tens-n, shear-p, tens-p shear-n, shear-p, tens-p
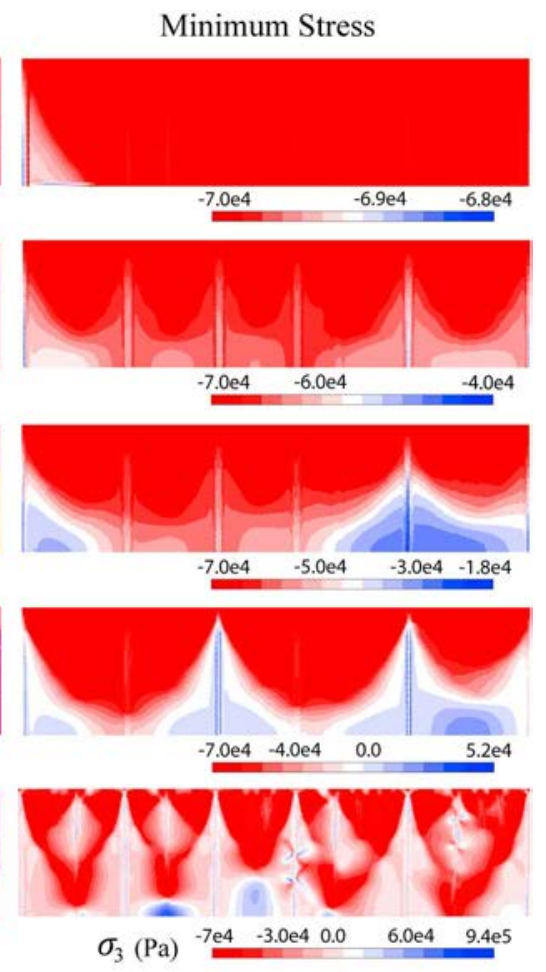

Figure 11. Five stages (lines a to e) of the evolution of $\sigma_{t}$, the mechanical state, and $\sigma_{3}$ during the horizontal extension of the model in Figure 8b. This model is more ductile than that in Figure $10\left(\varepsilon^{0}=10^{-2}\right.$ instead of $10^{-3}$ in the previous model).

in Figure 10, first column) are formed first due to the boundary effect, which is very small in the models, but does exist. In the second column in Figures 10a and 10b (mechanical state), one can also see the initiation of a regular pattern of subvertical bands that are not seen on the $\sigma_{t}$ plots, since the $\sigma_{t}$ reduction within these bands is very small at the early stages compared to the fractures already formed (these bands appear on the $\sigma_{t}$ maps after the change in color scale). At the next stage, the middle fracture in Figure 9 (the rightmost fracture in Figure 10b, first column) is formed. In the following description, we will refer only to the quarter model results. On the $\sigma_{3}$ plots (the third column in Fig. 10), one can see the formation of stress shadows at the sides of the formed fractures.

The sets of deformation bands (that are pure dilation bands) evolve further during the loading but very irregularly. In some of them, the failure along the most damaged axial zones is rapidly accelerated at certain deformation stages and ends in complete local material rupture (when $\sigma_{t}$ reaches zero) close to the upper boundary of the layer. Fractures emanating from these failed band segments propagate, with the tensile stress being concentrated at their tips (the third column in Figure 10).

In the above model the hardening modulus is very negative, $h=-0.26\left(\widetilde{\varepsilon}^{0}\right.$ is very small). In the model in Figure $11, \widetilde{\varepsilon}^{0}$ is an order of magnitude larger, $10^{-2}(h=-0.026)$. This model therefore is more ductile, which explains more gradual (or slow) fracturing. One can notice that the dilation bands are much thicker and longer than in the previous model (compare Figures 10a, 10b, and 11a, second column). There is a smaller number of underdeveloped (not crossing the entire model) fractures. On the contrary, the damage of the material is more distributed and involves practically the entire model (the second column in Figure 11), particularly within and in the vicinity of the fractures where inelastic deformation occurs due to both tensile and shear failure mechanisms (Figure 11e), unlike the previous model where only tensile mechanism is active (Figure 10) outside the bands. Another difference between the two models consists in the locations of the fracture initiation and the propagation direction. In Figure 11, the first six fractures propagate from the model bottom (which corresponds to the middle of the entire model) upward. The later fractures are initiated in the upper part of the model and propagate mostly downward, but upward as well. In Figure 10 all the fractures are initiated near the layer top. In spite of the differences in the fracturing 
a
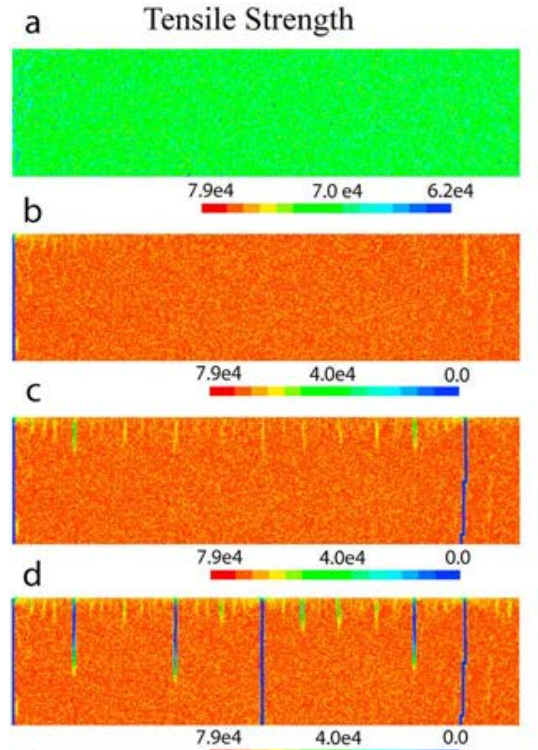

e

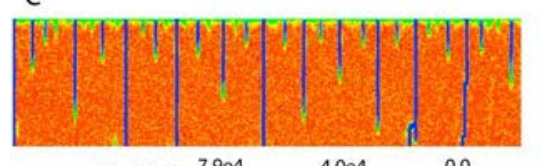

$\sigma_{t}(\mathrm{~Pa}){ }^{7.9 \mathrm{e} 4}$
Mechanical State
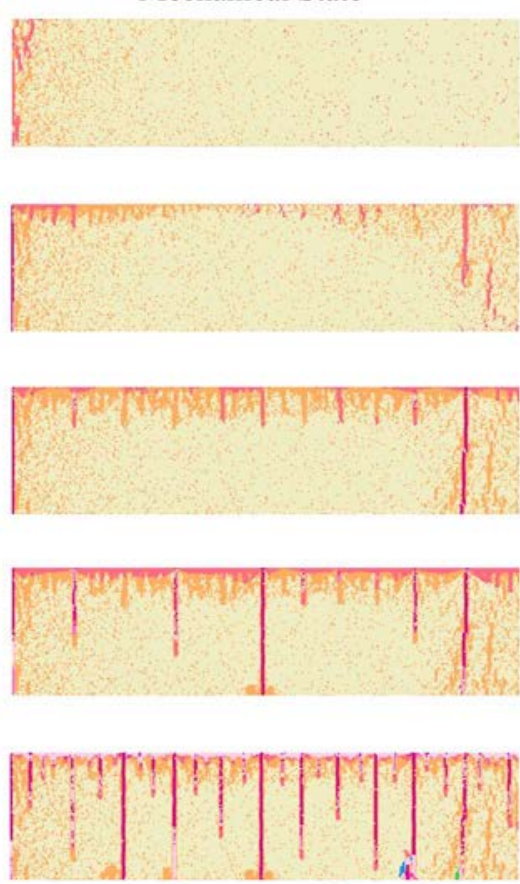

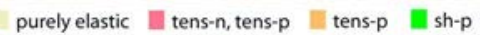

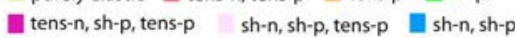
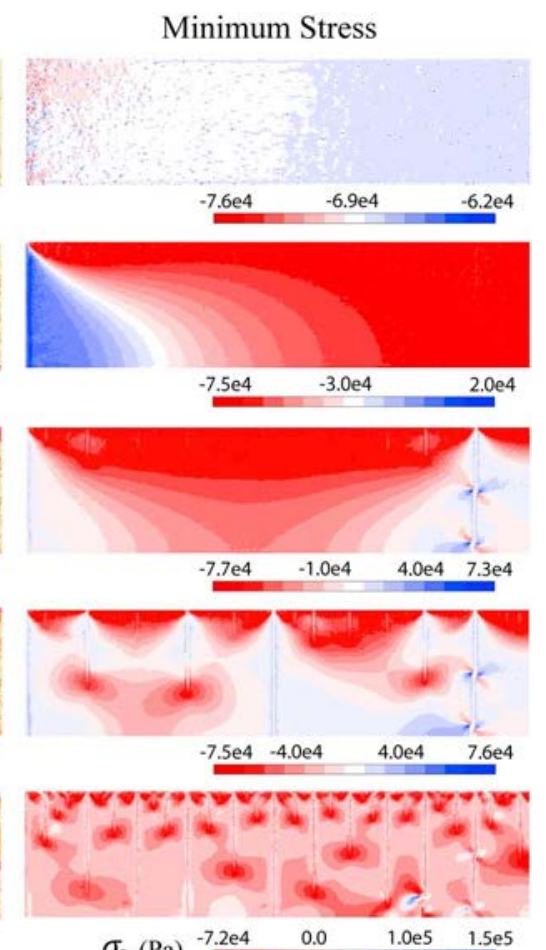

$\sigma_{3}(\mathrm{~Pa})-\frac{-7.2 \mathrm{e} 4}{2} \quad 0.0 \quad 1.0 \mathrm{e} 5 \quad 1.5 \mathrm{e} 5$

Figure 12. Five stages (lines a to e) of the evolution of $\sigma_{t}$, the mechanical state, and $\sigma_{3}$ during the horizontal extension of the model in Figure 8b. This model is the same as that in Figure 10 with the only difference that the initial tensile strength $\sigma_{t}^{0}$ is not uniform in this case but follows a Gaussian distribution over the numerical grid elements with a mean value of $7 \times 10^{4} \mathrm{~Pa}$ (as in other models) and a standard deviation of $2 \times 10^{3} \mathrm{~Pa}$.

a

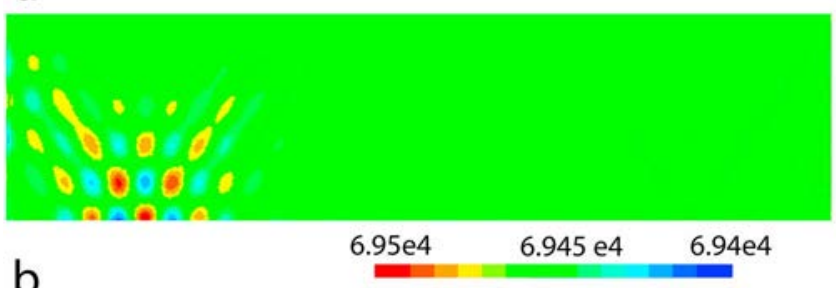

b
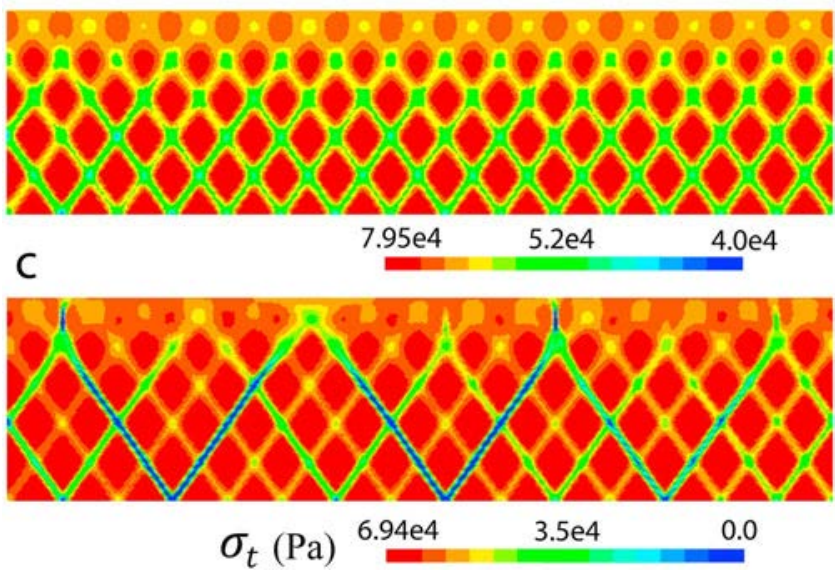

Figure 13. Stages of the evolution (a to c) of $\sigma_{t}$ during the horizontal extension of the model in Figure 8b loaded to higher stresses $\sigma_{z z}^{\text {ini }}=\sigma_{y y}^{\text {ini }}=6 \times 10^{5}$ Pa. $N_{\mathrm{X}}=320, \widetilde{\varepsilon}^{0}=10^{-2}$. processes in the above models, the number of fractures cutting the whole model is not very different, eight in Figure 10 and seven in Figure 11. The total number of fractures (including the underdeveloped ones) is much greater in the more brittle model in Figure 10. The increase of $\widetilde{\varepsilon}^{0}$ to $5 \times 10^{-2}$ further increases the ductility, but the number of fractures remains practically the same. Reducing $\widetilde{\varepsilon}^{0}$ to $5 \times 10^{-4}$ results in the reduction of the thickness of the upper part of the model affected by the dilation banding at the early stages, but this does not have a significant effect on the deformation process.

The models in Figures 10 and 11 reveal the role of ductility in structuring the fracture set. These models are homogeneous, so one might think that heterogeneous models with preexisting stress concentrators could behave differently (i.e., that the development of a fracture set could be prevented). Therefore, we present the model where the initial tensile strength $\sigma_{t}^{0}$ is not uniform but follows a Gaussian distribution over the numerical grid elements with a mean value of $7 \times 10^{4} \mathrm{~Pa}$ (as in the other models) and a standard deviation of $2 \times 10^{3} \mathrm{~Pa}$. The stress and strain fields do indeed become heterogeneous in this case (Figure 12), particularly at the initial deformation stages, but strain localization and fracturing finally occur similar to the model in Figure 10.

To complete the picture, we present one more model (Figure 13) run at a higher stress level $\left(\sigma_{z z}^{\text {ini }}=\sigma_{y y}^{\text {ini }}=6 \times 10^{5} \mathrm{~Pa}\right)$ corresponding to shear fracturing. The fracture in this model again starts with the formation of deformation localization bands (dilatant-shear this time), which is followed by the 
a
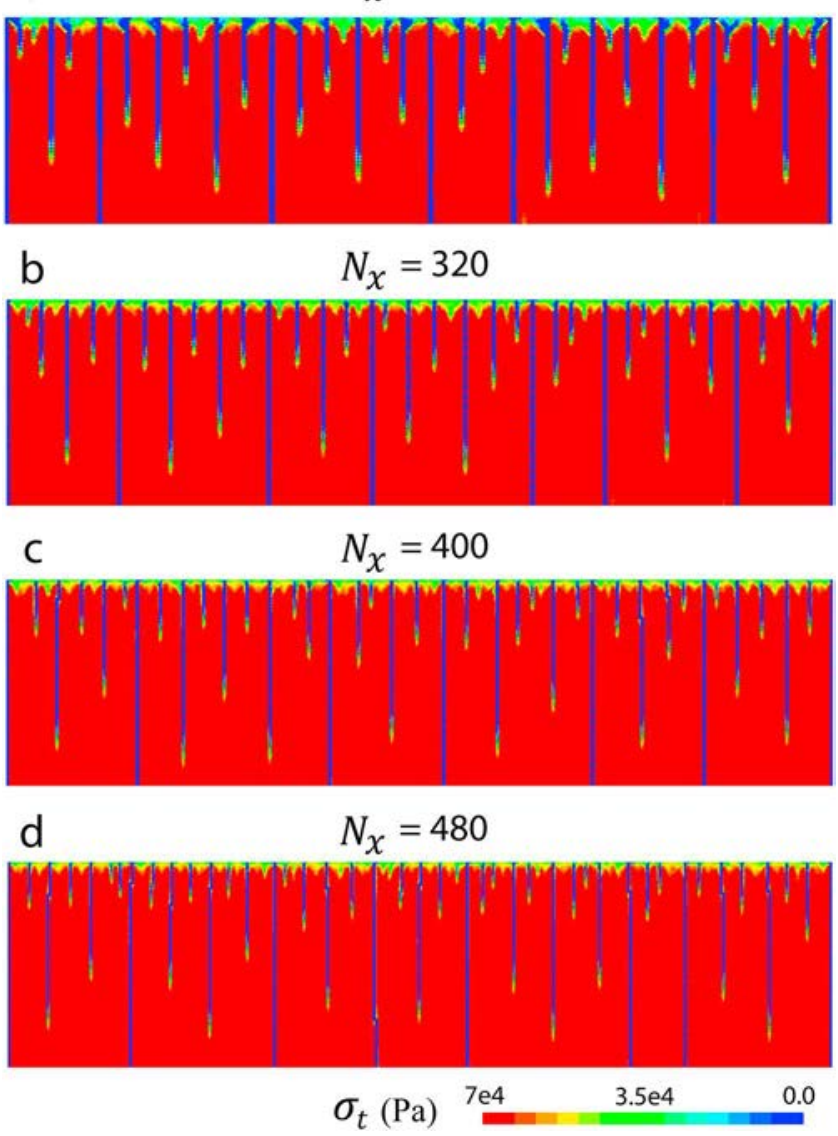

Figure 14. Four fractured models (a to d) that differ only by the grid resolution $\left(\right.$ by $\left.N_{x}\right) \cdot \widetilde{\varepsilon}^{0}=10^{-3}$ and $\sigma_{z z}^{\text {ini }}=\sigma_{y y}^{\text {ini }}=3.5 \times 10^{5} \mathrm{~Pa}$. All models correspond to the setup in Figure $8 \mathrm{~b}$, and were run to the same nominal horizontal extension strain of $-3 \times 10^{-3}$. evolution of certain bands to shear fractures when $\sigma_{t}$ reaches zero (Figure 13c).

Finally, in Figure 14 four more models are presented that differ only by the numerical resolution. They were run to the same horizontal extension $x$-displacement (or nominal horizontal strain) in order to reveal the mesh dependence of the modeling results. There is clear and expected mesh dependence of dilation band and fracture thicknesses (that are proportional to the grid element size). However, there is a very weak, practically negligible mesh dependence of a fracture pattern and its evolution, except that with $N_{x}$ increase, the number of the resolved short fractures initiated at the model top increases. At $N_{x}<200$, the mesh dependence becomes more significant. This suggests that the grid element size is satisfactorily taken into account in the constitutive formulation.

\section{Discussion}

The fracture (joint) sets generated in the numerical models resemble natural and experimental ones including some details (compare, for example, Figures 1, 6a, and 9 showing parallel joints propagated to different distances across the layer from its top and bottom). The fracture initiation in the initially homogeneous models is due to a constitutive instability that occurs under tensile stress and results in the localization of inelastic strain (damage) and the formation of pure dilation bands in a strain softening regime. The material strength (and hence the absolute value of the tensile stress) locally reduces to zero within the band during its evolution, which also causes a release of the tensile stress at the sides of a fractured band segment (formation of a stress shadow predicted by Bai \& Pollard, 2000). The fractures spontaneously initiated in this way propagate along their strike in Mode I or opening mode. Fracture initiation is thus preceded by localized damage within dilation bands, and fracture propagation follows band propagation as can be seen in Figures 10-12. The fractures in these figures (models) correspond to $\sigma_{t}=0$, and the dilation bands, to $0<\sigma_{t}<7 \times 10^{4} \mathrm{~Pa}$. The process zone in front and around the fracture tip therefore does not appear as a result of the stress concentration at the tip of the propagating fracture. This process zone is the result of deformation localization and formation of a dilation band that precedes and prepares the fracture. Therefore, the fractures propagate more easily in these elastoplastic models compared to what is predicted by LEFM that does not take into account inelastic strain and its evolution. Indeed, the minimum fracture spacing normalized by the layer thickness is 0.17 in Figure 9 and 0.13 in Figure 14d (or much less taking into account the underdeveloped fractures), whereas the minimum normalized spacing predicted from LEFM is about twice of that (Bai \& Pollard, 2000). LEFM predictions should approach the modeling results as $\varepsilon^{0}$ approaches zero, although the necessity to introduce the initial flaws explicitly (specifying their sizes, orientations, and distribution) will remain a major drawback of the LEFM approach.

\subsection{Fracture Orientation}

The presented results show that the primary process is not the direct fracture of a material (in the sense of separation of the two walls), but the initiation of deformation (damage) localization within narrow bands, the dilation bands. To induce jointing, these bands should be oriented normal to $\sigma_{3}$; otherwise, the bands will be shear and will lead to shear fracturing, Figure 13 (which occurs not as Mode II cracking but results from the propagation and evolution of dilatant-shear strain localization bands). What defines the orientation of the bands and more generally, what defines their formation? Deformation banding is caused by a material (or constitutive) instability resulting in deformation bifurcation that occurs at some point of elastoplastic loading when the hardening modulus $h$ reaches its critical value $h_{c r}$ (Rudnicki \& Rice, 1975). These authors have also shown that the orientation of the deformation bands in the stress space is defined by a constitutive 
model and its parameters (such as the internal friction and dilatancy coefficients) and by the deviatoric stress state. In this paper, we use a composite constitutive model (equations (1) and (2)), describing tensile and shear failure mechanisms. In both cases $h_{c r}$ can be shown to be zero (Ottosen \& Runesson, 1991; Vardoulakis, 1980 ; Vermeer, 1982), meaning that the strain localization can occur only at a nonpositive (in practice, negative) $h$ value, that is, in strain softening regime. Our numerical models confirm this conclusion and in all the presented models $h<0$. The angle $\psi$ the deformation band forms with $\sigma_{1}$ (which is vertical in the models) is predicted to be zero for the tensile failure model used (Ottosen \& Runesson, 1991); that is, the forming bands should be pure dilation bands, and

$$
\psi= \pm \frac{1}{2}\left[\frac{\pi}{2}-\operatorname{asin}\left[\frac{\alpha_{c}-1}{\alpha_{c}+1}\right]\right]
$$

for shear failure mechanism as can be obtained from (Vardoulakis, 1980; Vermeer, 1982). For the parameter values adopted in the present work, equation (7) yields $\psi= \pm 35.3^{\circ}$, which are exactly the values measured on Figure 13. Since the initiation of joints in the present numerical models is only due to the tensile failure mechanism (which can be inferred from the Mechanical State plots in Figures 10 and 11), the corresponding deformation bands are oriented at $\psi=0^{\circ}$; that is, they are pure dilation bands. The numerical models confirm that there is no shear displacement along these bands. Further evolution of the bands involves shear failure mechanism both within (Figures 10 and 11c-11e) and outside (Figures 11d and 11e) them, which does not change the fracture orientation at the macroscale (the contribution of the shear mechanism increases in the models with both $\varepsilon^{0}$ and the stress level). At a smaller scale (comparable to the initial band thickness $d$ ), the shear failure mechanism may result in both shear banding and fracturing, but these processes cannot be resolved by the continuum modeling.

As mentioned, the predictions of deformation bifurcation analysis (of the $\psi$ value in particular) depend on the constitutive model. A question arises naturally, do other (than the used associated cutoff) models predict $\psi=0^{\circ}$ and what will be the difference in the modeling of jointing when using these models? In fact, the dilation bands (bands with $\psi=0^{\circ}$ ) were initially theoretically predicted using the Drucker-Prager constitutive model (Issen \& Rudnicki, 2000; Ottosen \& Runesson, 1991; Perrin \& Leblond, 1993). According to the results of bifurcation analysis in these papers, the condition for the formation of the dilation bands can be written

$$
\beta \geq \frac{3 N(1-2 \nu)+3 \sqrt{4-3 N^{2}}-2 \mu(1+\nu)}{2(1+\nu)}
$$

where $\beta$ is the dilatancy factor, $\mu$ is the internal friction coefficient, and $N$ is the deviatoric stress state parameter that can vary from $-1 / \sqrt{3}$ to $1 / \sqrt{3}$ corresponding to axisymmetric extension and compression, respectively (this parameter can be expressed via the Lode angle). Assuming for $N$ its average value of $N=0$, corresponding to the pure shear, and the typical for rocks values $\mu=0.8$ and $\nu=0.25$, obtain from (8) $\beta \geq 1$.6. This is an unrealistically high value that has never been measured experimentally. In addition, it can be shown that such high $\beta$ values $(\beta>\mu)$ can lead to negative energy dissipation during plastic deformation, which violates the second law of thermodynamics. For axisymmetric extension, $N=-1 / \sqrt{3}, \beta$ is smaller, $\beta=0.93$, and for $N=1 / \sqrt{3}, \beta=1.63$. Therefore, the dilation (or dilatancy) bands obtained experimentally in Chemenda et al. (2011a) remained unexplained. A very simple associated cutoff model was not applied to tackle dilation banding. This model, however, now appears to be more adequate to describe dilatant failure at low pressure. Plastic energy dissipation is always nonnegative, and the dilatancy factor has a reasonable value for this model. Indeed, $\beta$ is defined as $\beta=d \varepsilon^{p} / d \bar{\gamma}^{p}$, where $d \bar{\gamma}^{p}$ is the increment of inelastic equivalent shear strain;

$$
\mathrm{d} \bar{\gamma}^{\mathrm{p}}=\sqrt{2\left[\left(\mathrm{~d} \varepsilon_{1}^{\mathrm{p}}-\mathrm{d} \varepsilon_{2}^{\mathrm{p}}\right)^{2}+\left(\mathrm{d} \varepsilon_{1}^{\mathrm{p}}-\mathrm{d} \varepsilon_{3}^{\mathrm{p}}\right)^{2}+\left(\mathrm{d} \varepsilon_{2}^{\mathrm{p}}-\mathrm{d} \varepsilon_{3}^{\mathrm{p}}\right)^{2}\right] / 3}
$$

As only $d \varepsilon_{3}^{p} \neq 0$ (see section 2.2 ), $\beta=\sqrt{3} / 2 \approx 0.87$ for any stress state.

It is interesting that the introduction of an arbitrary disorder into the model properties (and hence into the stress state during the inelastic straining) does not affect its capacity to generate regular band-fracture sets (Figure 12) as long as, obviously, an amplitude of this disorder does not exceed a certain value (its 


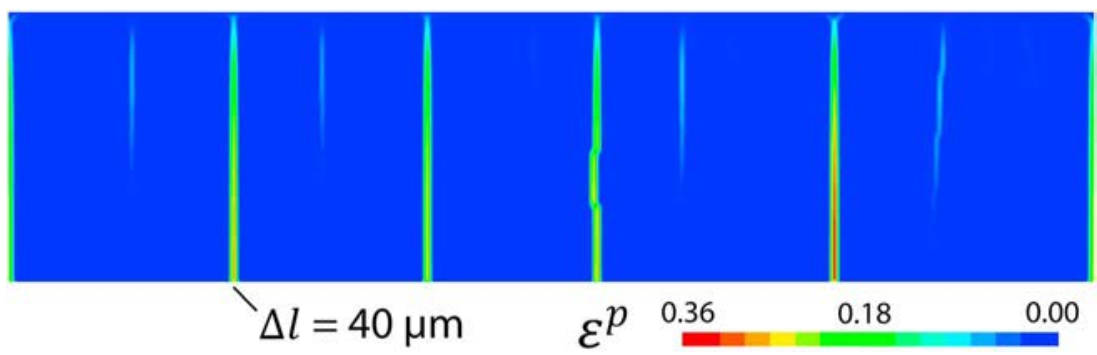

Figure 15. Contour plot of the accumulated inelastic volume strain $\varepsilon^{p}$ (equal to the porosity change induced by the inelastic deformation) corresponding to the last deformation stage in Figure 11. $\Delta l$ is the equivalent aperture of the fracture at the indicated location.

wavelength is important as well). In Figure 12 this amplitude is already far from being negligible: The maximum relative spatial variation of the tensile strength at a numerical grid element scale (corresponding to an assembly of grains) is $\sim 24 \%$ (Figure 12a). Larger heterogeneities in the properties can completely change the fracture pattern (Chemenda et al., 2018).

\subsection{Fracture Thickness}

There is no actual opening of the tensile fractures forming in the numerical models as they are continuum. The space that should be opened is filled in these models with the stretched material, which acquires an increased porosity. The fracture corresponds to the completely failed material for which $\sigma_{t}=0$. The porosity of the failed numerical zones acquired during deformation (in addition to the preexisting porosity) is equal to the accumulated inelastic volume strain $\varepsilon^{p}$ shown in Figure 15. The equivalent aperture $\Delta l$ of the fracture (joint) can be evaluated as

$$
\Delta l=\int_{0}^{\Delta d}\left[\varepsilon^{p}(x)-\varepsilon^{0}\right] d x \text { if } \varepsilon^{p}(x)>\varepsilon^{0}
$$

where $\Delta d$ is the total thickness of the completely failed zones and $x$ is oriented across the band. At the indicated position in Figure 15, the band thickness is $d=5 \times 10^{-4} \mathrm{~m}, \Delta d=1.4 \times 10^{-4} \mathrm{~m}$, and $\varepsilon^{p}(x)$ is obtained from Figure 15 (note that the band thickness that appears in this figure is much smaller than the actual one, $d$, seen in Figure 11a, second column, because of a very strong $\varepsilon^{p}(x)$ gradient). Substituting these into equation (9), obtain $\Delta l=4 \times 10^{-5} \mathrm{~m}=40 \mu \mathrm{m}$. The apparent aperture of the same fracture decreases upward and reaches $\sim 10$ times smaller value at the layer top.

As indicated, the fracture corresponds to the axial zone of the dilation or porosity band with strongly increased porosity. The band thickness $d$ increases with the increase of $\widetilde{\varepsilon}^{0}$ or of the ductility, which itself grows with the stress level or pressure. The contribution of shear failure mechanism in inelastic deformation both within and outside deformation bands also increases with $\widetilde{\varepsilon}^{0}$ (Figure 11e) and with pressure (Figure 13). This deformation is distributed smoothly in the models, but in reality, it should bifurcate and lead to small (micro) deformation bands and fractures of different types that cannot be resolved in continuum models as indicated above. These features should roughen the fracture walls, and it is logical to suppose that the thicker the fracture-related damage zone (deformation band), the greater the amplitude of the roughnesses that are organized into plumose patterns as suggested by both experimental (Figures $4,6 \mathrm{~b}, 6 \mathrm{c}$ ) and field observations. Such an organization is due to the fact that the bands in the models are propagating features; the fractures propagate within the bands with a certain delay.

\subsection{Fracture Propagation Direction}

The location of fracture initiation points and the propagation direction again depend on the material ductility (on $\varepsilon^{0}$ ). At a relatively small $\varepsilon^{0}$ (low pressure), the fractures are initiated near the top and bottom of the layer and propagate toward its center (Figures 9 and 10). This was also predicted by Bai and Pollard (2000). In a more ductile material (larger $\varepsilon^{0}$ ), the first fractures are initiated in the middle of the layer and propagate to the top and the bottom (Figure 11). The next fractures are initiated in the lower and upper parts of the layer (the upper part in Figure 11e). Thus, the initiation points can be located anywhere, which also 
seems to be the case for natural joints, although joint initiation at bed boundaries is more common (de Joussineau et al., 2005; Helgeson \& Aydin, 1991; Savalli \& Engelder, 2005). This is the case in the GRAM experiment in Figure 6 as well. Careful inspection of the photo in Figure 6a (which has a sufficiently high resolution) reveals several underdeveloped fractures emanating from the top and bottom of the layer, very like as in the model in Figure 9. A similar natural fracture pattern (and likely history as well) is seen in Figure 1 in 3-D and was also documented in basaltic lava affected by columnar jointing (Aydin \& DeGraff, 1988).

\subsection{Fracture Spacing}

Although the total number of fractures cutting the entire model layer does not much depend on the ductility degree or on $\varepsilon^{0}$ (compare Figures 10 and 11), the capacity of fracture generation is clearly higher in a more brittle material (with lower $\varepsilon^{0}$ ). Most of the fractures propagate to a certain distance but do not cut completely the model. This propagation in the presented 2-D models occurs only in the vertical direction. In a 3-D context, the fracture propagation also should occur in the horizontal direction as is the case in nature (e.g., de Joussineau et al., 2005; Pollard \& Aydin, 1988; Savalli \& Engelder, 2005). This can increase fracture density in each $\sigma_{2}$-normal section.

All stresses in this paper should be obviously considered as effective, but the actual modeling of the coupling between pore pressure and deformation may allow further increase of fracture density. The influence of the softening rule (equation (2)) should be investigated as well. We assumed a simple linear rule (as there are neither experimental nor theoretical constraints on it), but other functions can be tested as well. The contrast in the elastic moduli and the thicknesses of the adjacent layers can also affect the results, although we made several tests that did not show any significant impact. On the other hand, the thickness of the fracturing layer $H$ clearly affects the fracture spacing, which scales with $H$. This is in agreement with the conclusions made on the basis of LEFM (Bai \& Pollard, 2000). The underdeveloped fractures obtained in the models may grow during the unloading (related to exhumation, for example) due to the spatial variation of the inelastic volume (porosity) acquired during the jointing. This can be tested in future modeling and may explain (at least partially) the apparent lack of barren joints in subsurface compared to outcrops (Gale et al., 2014). Finally, integrating into the models of the cementation (strengthening) of fractures during their opening due to the mineral fill (Fall et al., 2015; Gale et al., 2014) can change both the evolution of a fracture set and the fracture density.

\section{Conclusions}

This study suggests that regular joint sets or networks widely present in outcrops (notably in sedimentary series, but in other rocks as well) do not form as the addition of individual brittle cracks emanating from preexisting material or structural heterogeneities (stress concentrators). They result from a material instability leading to the initiation of a network of narrow bands of localized dilatant damage (inelastic deformation) within large rock volumes. These bands are pure dilation bands that are normal to $\sigma_{3}$. They form (are initiated) due to the inelastic (plastic or ductile) straining of a rock volume that occurs even in a brittle deformation regime (very low pressure). The band thickness, length, and the initial (before a phase of rapid fracture) gradual strength reduction (failure) within them increase with the material ductility, which grows with the effective stress level $\left(\sigma_{1}\right)$ or pressure. The strength reduction within the bands is accelerated at a certain stage of their evolution and locally reaches zero, resulting in fracture initiation. The initial fracture then propagates in Mode I within the band following the band propagation. The delay of fracture propagation with respect to the band propagation (the distance between the fracture and band tips, which corresponds to the process zone) increases with the material ductility (with pressure). The fracture (joint) appears thus as a band of damaged material with increased porosity, which is maximum along the band axial zone where the material is completely broken. The material within the band undergoes both tensile and shear damage. Shear damage increases with ductility increase, which also leads to band thickness increase in the numerical models. We believe that these processes can result in small (band thickness)-scale oblique shear fractures within the band, which are not resolved by the continuum models and which can cause an increase in the roughness of fracture walls as is evidenced by the laboratory experiments. Since the dilation bands and the fractures that follow them are propagating features, these roughnesses create a sort of streamlines organized in plumose patterns typical of both natural and experimentally generated joints. 


\section{Nomenclature}

\begin{tabular}{|c|c|}
\hline$E$ & Young's modulus \\
\hline$\nu$ & Poisson's ratio \\
\hline$G$ & Shear modulus \\
\hline$\varepsilon^{p}$ & Accumulated inelastic (plastic) volume strain \\
\hline $\bar{\gamma}^{p}$ & Accumulated inelastic equivalent shear strain \\
\hline$\sigma_{t}\left(\varepsilon^{p}\right)$ & Tensile strength which is function of $\varepsilon^{p}$ \\
\hline$\sigma_{t}^{0}$ & Initial (at $\left.\varepsilon^{p}=0\right)$ tensile strength \\
\hline$\sigma_{c}\left(\varepsilon^{p}\right)$ & Unconfined (uniaxial) compression strength \\
\hline$\sigma_{\mathrm{c}}^{0}$ & Initial value of $\sigma_{c}$ \\
\hline$\alpha_{c}$ & Parameter in Coulomb-type yield function (equation (1) and Figure 2) \\
\hline$\sigma_{\text {int }}\left(\varepsilon^{p}\right)$ & Equal to $\sigma_{1}$ at the intersection of tensile and shear yield envelopes in Figures 3 and 7 \\
\hline$\sigma_{\text {int }}^{0}$ & Initial value of $\sigma_{\text {int }}$ \\
\hline$\varepsilon^{0}$ & Inelastic volume strain at which both $\sigma_{t}$ and $\sigma_{c}$ reach zero \\
\hline$P_{c}$ & Confining pressure \\
\hline$\sigma_{\mathrm{i}}$ & Principal stresses, compression positive, $i=1,2,3$ \\
\hline$q=\sigma_{1}-\sigma_{3}$ & Differential stress \\
\hline$F, F_{t}, F_{S}$ & Yield functions defined in equation (1) \\
\hline$\Phi$ & Plastic potential \\
\hline$h$ & Hardening modulus \\
\hline$\Delta z$ & Numerical grid element (zone) size \\
\hline$d$ & Thickness of the deformation band in numerical models \\
\hline$d_{R}$ & Real thickness of deformation bands in laboratory experiments or nature \\
\hline$\Delta d$ & Total thickness of the completely failed numerical grid zones within a deformation band \\
\hline$\Delta l$ & Equivalent fracture opening in the numerical models \\
\hline$H$ & Bed (layer) thickness \\
\hline$\lambda$ & Fracture spacing \\
\hline$C, \widetilde{\varepsilon}^{0}$ & Defined in equation (6) \\
\hline$\varepsilon_{i}^{p}$ & Inelastic principal strains, $i=1,2,3$ \\
\hline$\psi$ & Angle between fracture or deformation band and $\sigma_{1}$ direction \\
\hline$\beta$ & Dilatancy factor \\
\hline$\mu$ & Internal friction coefficient \\
\hline$N$ & Deviatoric stress-state parameter \\
\hline$\sigma_{x x}^{\mathrm{ini}}, \sigma_{y y}^{\mathrm{ini}}, \sigma_{z z}^{\mathrm{ini}}$ & Initial stresses applied in the numerical models \\
\hline GRAM & Granular Rock Analogue Material \\
\hline
\end{tabular}

Acknowledgments

I thank Jean-Pierre Petit for numerous discussions and the anonymous reviewers for useful suggestions. The numerical data are available in the figures of this manuscript.

\section{References}

Ashby, M. F., \& Sammis, C. G. (1990). The damage mechanics of brittle solids in compression. Pure and Applied Geophysics, 133(3), 489-521. https://doi.org/10.1007/BF00878002

Aydin, A., \& DeGraff, J. M. (1988). Evolution of polygonal fracture patterns in lava flows. Science, 239(4839), 471-476. https://doi.org/ 10.1126/science.239.4839.471

Bahat, D. (1991). Tectonofractography. In Tectonofractography, (pp. 239-324). Berlin, Heidelberg: Springer. https://doi.org/10.1007/978-3642-76162-1_5

Bai, T., \& Pollard, D. D. (2000). Closely spaced fractures in layered rocks: Initiation mechanism and propagation kinematics. Journal of Structural Geology, 22(10), 1409-1425. https://doi.org/10.1016/S0191-8141(00)00062-6

Baud, P., Schubnel, A., \& Wong, T. F. (2000). Dilatancy, compaction, and failure mode in Solnhofen limestone. Journal of Geophysical Research, 105(B8), 19,289-19,303. https://doi.org/10.1029/2000JB900133

Bésuelle, P., Desrues, J., \& Raynaud, S. (2000). Experimental characterisation of the localisation phenomenon inside a Vosges sandstone in a triaxial cell. International Journal of Rock Mechanics and Mining Sciences, 37(8), 1223-1237. https://doi.org/10.1016/S13651609(00)00057-5

Blès, J. L., \& Feuga, B. (1986). The fracture of rocks, (p. 131). New York: Elsevier.

Bobich, J. K. (2005). Experimental analysis of the extension to shear fracture transition in Berea Sandstone (Doctoral dissertation, Texas A\&M University).

Chang, C., \& Haimson, B. (2000). True triaxial strength and deformability of the German Continental Deep Drilling Program (KTB) deep hole amphibolite. Journal of Geophysical Research, 105(B8), 18,999-19,013. https://doi.org/10.1029/2000JB900184

Chemenda, A. I. (2007). The formation of shear-band/fracture networks from a constitutive instability: Theory and numerical experiment. Journal of Geophysical Research, 112, B11404. https://doi.org/10.1029/2007JB005026 
Chemenda, A. I. (2009). The formation of tabular compaction-band arrays: Theoretical and numerical analysis. Journal of the Mechanics and Physics of Solids, 57(5), 851-868. https://doi.org/10.1016/j.jmps.2009.01.007

Chemenda, A. I., Ambre, J., Chen, J., Fan, J., Petit, J. P., \& Jiang, D. (2018). Role of heterogeneities in jointing (fracturing) of geological media: Numerical analysis of fracture mechanisms. Comptes Rendus Geoscience, 350(8), 452-463. https://doi.org/10.1016/j. crte.2018.06.009

Chemenda, A. I., \& Mas, D. (2016). Dependence of rock properties on the Lode angle: Experimental data, constitutive model, and bifurcation analysis. Journal of the Mechanics and Physics of Solids, 96, 477-496. https://doi.org/10.1016/j.jmps.2016.08.004

Chemenda, A. I., Nguyen, S. H., Petit, J. P., \& Ambre, J. (2011a). Mode I cracking versus dilatancy banding: Experimental constraints on the mechanisms of extension fracturing. Journal of Geophysical Research, 116, B04401. https://doi.org/10.1029/2010JB008104

Chemenda, A. I., Nguyen, S. H., Petit, J. P., \& Ambre, J. (2011b). Experimental evidences of transition from mode I cracking to dilatancy banding. Comptes Rendus Mécanique, 339(4), 219-225. https://doi.org/10.1016/j.crme.2011.01.002

Chen, Z., \& Schreyer, H. L. (1987). Simulation of soil-concrete interfaces with nonlocal constitutive models. Journal of Engineering Mechanics, 113(11), 1665-1677. https://doi.org/10.1061/(ASCE)0733-9399(1987)113:11(1665)

de Joussineau, G., Bazalgette, L., Petit, J. P., \& Lopez, M. (2005). Morphology, intersections, and syn/late-diagenetic origin of vein networks in pelites of the Lodève Permian Basin, Southern France. Journal of Structural Geology, 27(1), 67-87. https://doi.org/10.1016/j. jsg.2004.06.016

Du Bernard, X., Eichhubl, P., \& Aydin, A. (2002). Dilation bands: A new form of localized failure in granular media. Geophysical Research Letters, 29(24), 2176. https://doi.org/10.1029/2002GL015966

Dunn, D. E., LaFountain, L. J., \& Jackson, R. E. (1973). Porosity dependence and mechanism of brittle fracture in sandstones. Journal of Geophysical Research, 78(14), 2403-2417. https://doi.org/10.1029/JB078i014p02403

Engelder, T., Lash, G. G., \& Uzcátegui, R. S. (2009). Joint sets that enhance production from Middle and Upper Devonian gas shales of the Appalachian Basin. AAPG Bulletin, 93(7), 857-889. https://doi.org/10.1306/03230908032

Fall, A., Eichhubl, P., Bodnar, R. J., Laubach, S. E., \& Davis, J. S. (2015). Natural hydraulic fracturing of tight-gas sandstone reservoirs, Piceance Basin, Colorado. Bulletin, 127(1-2), 61-75. https://doi.org/10.1130/B31021.1

Fortin, J., Stanchits, S., Dresen, G., \& Guéguen, Y. (2006). Acoustic emission and velocities associated with the formation of compaction bands in sandstone. Journal of Geophysical Research, 111, B10203. https://doi.org/10.1029/2005JB003854

Fossen, H. (2016). Structural geology. Cambridge: Cambridge University Press.

Fossen, H., Schultz, R. A., Shipton, Z. K., \& Mair, K. (2007). Deformation bands in sandstone: A review. Journal of the Geological Society, 164(4), 755-769. https://doi.org/10.1144/0016-76492006-036

Gale, J. F., Laubach, S. E., Olson, J. E., Eichhubl, P., \& Fall, A. (2014). Natural fractures in shale: A review and new observations. AAPG Bulletin, 98(11), 2165-2216. https://doi.org/10.1306/08121413151

Griggs, D. T., \& Handin, J. (1960). Observations on fracture and a hypothesis of earthquakes. In D. T. Griggs, \& J. Handin (Eds.), Rock deformation, Geological Society of America Memoirs, (Vol. 79, pp. 347-373). New York: Geological Society of America. https://doi.org/ 10.1130/MEM79-p347

Hallbauer, D. K., Wagner, H. N. G. W., \& Cook, N. G. W. (1973). Some observations concerning the microscopic and mechanical behaviour of quartzite specimens in stiff, triaxial compression tests. In International Journal of Rock Mechanics and Mining Sciences \& Geomechanics Abstracts, (Vol. 10, pp. 713-726). Pergamon: Elsevier. https://doi.org/10.1016/0148-9062(73)90015-6

Helgeson, D. E., \& Aydin, A. (1991). Characteristics of joint propagation across layer interfaces in sedimentary rocks. Journal of Structural Geology, 13(8), 897-911. https://doi.org/10.1016/0191-8141(91)90085-W

Issen, K. A., \& Rudnicki, J. W. (2000). Conditions for compaction bands in porous rock. Journal of Geophysical Research, 105(B9), 21,529-21,536. https://doi.org/10.1029/2000JB900185

Itasca (2013). Fast Lagrangian analysis of continua in 3-dimensions, version 5.0, manual. Itasca, Minnesota.

Jorand, C., Chemenda, A. I., \& Petit, J. P. (2012). Formation of parallel joint sets and shear band/fracture networks in physical models Tectonophysics, 581, 84-92. https://doi.org/10.1016/j.tecto.2011.11.021

Katz, O., \& Reches, Z. E. (2004). Microfracturing, damage, and failure of brittle granites. Journal of Geophysical Research, 109(B1), B01206. https://doi.org/10.1029/2002JB001961

Ma, X., \& Haimson, B. C. (2016). Failure characteristics of two porous sandstones subjected to true triaxial stresses. Journal of Geophysical Research: Solid Earth, 121, 6477-6498. https://doi.org/10.1002/2016JB012979

Mas, D., \& Chemenda, A. I. (2014). Dilatancy factor constrained from the experimental data for rocks and rock-type material. International Journal of Rock Mechanics and Mining Sciences, 67, 136-144. https://doi.org/10.1016/j.ijrmms.2013.12.014

Mas, D., \& Chemenda, A. I. (2015). An experimentally constrained constitutive model for geomaterials with simple friction-dilatancy relation in brittle to ductile domains. International Journal of Rock Mechanics and Mining Sciences, 77, 257-264. https://doi.org/10.1016/ j.ijrmms.2015.04.013

McConaughy, D. T., \& Engelder, T. (2001). Joint initiation in bedded clastic rocks. Journal of Structural Geology, 23(2-3), 203-221. https:// doi.org/10.1016/S0191-8141(00)00091-2

Needleman, A. (1988). Material rate dependence and mesh sensitivity in localization problems. Computer Methods in Applied Mechanics and Engineering, 67(1), 69-85. https://doi.org/10.1016/0045-7825(88)90069-2

Nguyen, G. D., \& Korsunsky, A. M. (2008). Development of an approach to constitutive modelling of concrete: Isotropic damage coupled with plasticity. International Journal of Solids and Structures, 45(20), 5483-5501. https://doi.org/10.1016/j.ijsolstr.2008. 05.029

Nguyen, S. H., Chemenda, A. I., \& Ambre, J. (2011). Influence of the loading conditions on the mechanical response of granular materials as constrained from experimental tests on synthetic rock analogue material. International Journal of Rock Mechanics and Mining Sciences, 48(1), 103-115. https://doi.org/10.1016/j.ijrmms.2010.09.010

Olson, J. E., Laubach, S. E., \& Lander, R. H. (2009). Natural fracture characterization in tight gas sandstones: Integrating mechanics and diagenesis. AAPG Bulletin, 93(11), 1535-1549. https://doi.org/10.1306/08110909100

Ottosen, N. S., \& Runesson, K. (1991). Properties of discontinuous bifurcation solutions in elasto-plasticity. International Journal of Solids and Structures, 27(4), 401-421. https://doi.org/10.1016/0020-7683(91)90131-X

Paterson, M. S., \& Wong, T. F. (2005). Experimental rock deformation-The Brittle Field. New York: Spinger-Verlag.

Perrin, G., \& Leblond, J. B. (1993). Rudnicki and Rice's analysis of strain localization revisited. Journal of Applied Mechanics, 60(4), 842-846. https://doi.org/10.1115/1.2900992

Petit, J. P., \& Barquins, M. (1988). Can natural faults propagate under mode II conditions? Tectonics, 7(6), 1243-1256. https://doi.org/ 10.1029/TC007i006p01243 
Pijaudier-Cabot, G., \& Bažant, Z. P. (1987). Nonlocal damage theory. Journal of Engineering Mechanics, 113(10), 1512-1533. https://doi.org/ 10.1061/(ASCE)0733-9399(1987)113:10(1512)

Poh, L. H., \& Swaddiwudhipong, S. (2009). Over-nonlocal gradient enhanced plastic-damage model for concrete. International Journal of Solids and Structures, 46(25-26), 4369-4378. https://doi.org/10.1016/j.ijsolstr.2009.08.025

Pollard, D. D., \& Aydin, A. (1988). Progress in understanding jointing over the past century. Geological Society of America Bulletin, 100(8), 1181-1204. https://doi.org/10.1130/0016-7606(1988)100<1181:PIUJOT>2.3.CO;2

Potyondy, D. O., \& Cundall, P. A. (2004). A bonded-particle model for rock. International Journal of Rock Mechanics and Mining Sciences, 41(8), 1329-1364. https://doi.org/10.1016/j.ijrmms.2004.09.011

Ramsay, J. G., \& Huber, M. I. (1987). The techniques of modern structural geology: Folds and fractures (Vol. 2). London: Academic Press.

Rawnsley, K. D., Peacock, D. C. P., Rives, T., \& Petit, J. P. (1998). Joints in the Mesozoic sediments around the Bristol Channel Basin. Journal of Structural Geology, 20(12), 1641-1661. https://doi.org/10.1016/S0191-8141(98)00070-4

Rice, J. R. (1976). The localization of plastic deformation. In W. T. Koiter (Ed.), Theoretical and Applied Mechanics, Proceedings of the 14th International Congress on Theoretical and Applied Mechanics, (Vol. 1, pp. 207-220). Delft: North-Holland Publishing Co.

Rives, T., Razack, M., Petit, J. P., \& Rawnsley, K. D. (1992). Joint spacing: Analogue and numerical simulations. Journal of Structural Geology, 14(8-9), 925-937. https://doi.org/10.1016/0191-8141(92)90024-Q

Rodriguez, E. (2005). A microstructural study of the extension-to-shear fracture transition in Carrara marble (Master dissertation, Texas A\&M University)

Rudnicki, J. W. (2017). A three invariant model of failure in true triaxial tests on Castlegate sandstone. International Journal of Rock Mechanics and Mining Sciences, 97, 46-51. https://doi.org/10.1016/j.ijrmms.2017.06.007

Rudnicki, J. W., \& Rice, J. R. (1975). Conditions for the localization of deformation in pressure-sensitive dilatant materials. Journal of the Mechanics and Physics of Solids, 23(6), 371-394. https://doi.org/10.1016/0022-5096(75)90001-0

Savalli, L., \& Engelder, T. (2005). Mechanisms controlling rupture shape during subcritical growth of joints in layered rocks. Geological Society of America Bulletin, 117(3), 436-449. https://doi.org/10.1130/B25368.1

Segall, P., \& Pollard, D. D. (1983). Joint formation in granitic rock of the Sierra Nevada. Geological Society of America Bulletin, 94(5), 563-575. https://doi.org/10.1130/0016-7606(1983)94<563:JFIGRO >2.0.CO;2

Tapponnier, P., \& Brace, W. F. (1976). Development of stress-induced microcracks in Westerly granite. International Journal of Rock Mechanics and Mining Science and Geomechanics Abstracts, 13(4), 103-112. https://doi.org/10.1016/0148-9062(76)91937-9

Vardoulakis, I. (1980). Shear band inclination and shear modulus of sand in biaxial tests. International Journal for Numerical and Analytical Methods in Geomechanics, 4(2), 103-119. https://doi.org/10.1002/nag.1610040202

Vardoulakis, I. (1989). Shear-banding and liquefaction in granular materials on the basis of a Cosserat continuum theory. Ingenieur Archiv, 59(3), 197-208. https://doi.org/10.1007/BF00532250

Vermeer, P. A. (1982). A simple shear-band analysis using compliances. In Proceedings of the IUTAM Conference on Deformation and Failure of Granular Materials, (pp. 493-499). Rotterdam: A.A. Balkema.

Wong, T. F., \& Baud, P. (2012). The brittle-ductile transition in porous rock: A review. Journal of Structural Geology, 44, 25-53. https://doi. org/10.1016/j.jsg.2012.07.010

Wong, T. F., David, C., \& Zhu, W. (1997). The transition from brittle faulting to cataclastic flow in porous sandstones: Mechanical defor mation. Journal of Geophysical Research, 102(B2), 3009-3025. https://doi.org/10.1029/96JB03281

Woodworth, J. B. (1896). On the fracture system of joints: With remarks on certain fractures. Boston Society of Natural History.

Younes, A. I., \& Engelder, T. (1999). Fringe cracks: Key structures for the interpretation of the progressive Alleghanian deformation of the Appalachian plateau. Geological Society of America Bulletin, 111(2), 219-239. https://doi.org/10.1130/0016-7606(1999)111<0219: FCKSFT>2.3.CO;2 